OPEN ACCESS

Edited by:

Jeanne Marie Fair,

Los Alamos National Laboratory

(DOE), United States

Reviewed by:

Takafira Mduluza

University of Zimbabwe, Zimbabwe

Juulia Jylhävä,

Karolinska Institutet (KI), Sweden

*Correspondence: JinSong Geng

gjs@ntu.edu.cn

Specialty section:

This article was submitted to Infectious Diseases - Surveillance,

Prevention and Treatment,

a section of the journal

Frontiers in Medicine

Received: 28 July 2020

Accepted: 05 August 2021

Published: 01 September 2021

Citation

Geng J, Yu X, Bao H, Feng Z, Yuan X,

Zhang J, Chen X, Chen Y, Li C and

Yu H (2021) Chronic Diseases as a

Predictor for Severity and Mortality of COVID-19: A Systematic Review With

Cumulative Meta-Analysis.

Front. Med. 8:588013.

doi: 10.3389/fmed.2021.588013

\section{Chronic Diseases as a Predictor for Severity and Mortality of COVID-19: A Systematic Review With Cumulative Meta-Analysis}

\author{
JinSong Geng ${ }^{1 *}$, XiaoLan Yu ${ }^{1}$, HaiNi Bao ${ }^{1}$, Zhe Feng ${ }^{1}$, XiaoYu Yuan ${ }^{2}$, JiaYing Zhang ${ }^{1}$, \\ XiaoWei Chen ${ }^{3}$, YaLan Chen ${ }^{1}$, ChengLong $\mathrm{Li}^{1}$ and Hao $\mathrm{Yu}^{4}$ \\ ${ }^{1}$ Department of Medical Informatics, Medical School of Nantong University, Nantong, China, ${ }^{2}$ Department of Emergency \\ Medicine, Affiliated Hospital of Nantong University, Nantong, China, ${ }^{3}$ Library and Reference Department, Zhejiang University \\ School of Medicine First Affiliated Hospital, Hangzhou, China, ${ }^{4}$ Department of Population Medicine, Harvard Medical School \\ and Harvard Pilgrim Health Care Institute, Boston, MA, United States
}

Introduction: Given the ongoing coronavirus disease 2019 (COVID-19) pandemic and the consequent global healthcare crisis, there is an urgent need to better understand risk factors for symptom deterioration and mortality among patients with COVID-19. This systematic review aimed to meet the need by determining the predictive value of chronic diseases for COVID-19 severity and mortality.

Methods: We searched PubMed, Embase, Web of Science, and Cumulative Index to Nursing and Allied Health Complete to identify studies published between December 1 , 2019, and December 31, 2020. Two hundred and seventeen observational studies from 26 countries involving 624,986 patients were included. We assessed the risk of bias of the included studies and performed a cumulative meta-analysis.

Results: We found that among COVID-19 patients, hypertension was a very common condition and was associated with higher severity, intensive care unit (ICU) admission, acute respiratory distress syndrome, and mortality. Chronic obstructive pulmonary disease was the strongest predictor for COVID-19 severity, admission to ICU, and mortality, while asthma was associated with a reduced risk of COVID-19 mortality. Patients with obesity were at a higher risk of experiencing severe symptoms of COVID-19 rather than mortality. Patients with cerebrovascular disease, chronic liver disease, chronic renal disease, or cancer were more likely to become severe COVID-19 cases and had a greater probability of mortality.

Conclusions: COVID-19 patients with chronic diseases were more likely to experience severe symptoms and ICU admission and faced a higher risk of mortality. Aggressive strategies to combat the COVID-19 pandemic should target patients with chronic diseases as a priority.

Keywords: chronic diseases, COVID-19, systematic review, cumulative meta-analysis, severity, mortality 


\section{INTRODUCTION}

Coronavirus disease 2019 (COVID-19) is an infectious disease caused by severe acute respiratory syndrome coronavirus 2 (SARS-CoV-2). The COVID-19 outbreak was declared as a public health emergency of international concern by the World Health Organization (WHO) on January 30, 2020 (1). Since then, the disease has been spreading quickly around the world, reaching 9.296 million cases and 479,133 deaths as of June 25, 2020 (2). The ongoing COVID-19 pandemic has led to a rapidly growing demand for healthcare facilities and healthcare workers, leaving healthcare systems in many countries overstretched and unable to perform effectively (3).

The COVID-19 symptoms range from very mild to severe problems. While it was reported that the majority of COVID-19 cases were mild and required limited treatment (4), those patients with severe COVID-19 might need hospitalization or intensive care and have worse outcomes, such as death. Identifying risk factors for serious cases and mortality can be helpful in guiding public health interventions for protecting the most vulnerable groups of the population from COVID-19. For example, the risk factor information can be used to design risk stratification tools and clinical pathways, thus establishing more effective early intervention strategies and resource allocation policies.

COVID-19 is a serious global health threat, with more than 99\% of confirmed cases currently coming from countries outside China. However, the vast majority of the published review articles relied almost exclusively on the studies conducted in China (511). In fact, several published reviews included data from only few countries outside China (12-14). Consequently, the limited information prevented decision-makers and patients from better recognizing the global evidence about risk factors for adverse COVID-19 outcomes. In addition, there is a serious concern about the validity and generalizability of the evidence on risk factors in COVID-19 patients generated by the published review articles, which failed to address the clinical heterogeneity of patients with COVID-19 among the observational studies. For instance, a meta-analysis (11) combined data from intensive care unit (ICU) admission and mortality into a single effect measure to find risk factors for progression of COVID-19, while another meta-analysis (8) pooled data from patients with severe COVID19 symptoms and those who were admitted to the ICU into one group. Further systematic reviews are needed to address this issue of patient heterogeneity to improve the validity and generalizability of the evidence.

This paper aimed to fill the gap by conducting a systematic review with meta-analysis to determine the predictive value of chronic diseases for the severity and mortality of COVID-19. Our analysis examined global evidence to generate systematic and robust findings. To our knowledge, this study represented the most comprehensive meta-analysis of COVID-19 severity, mortality, ICU admission, and acute respiratory distress syndrome (ARDS). Furthermore, it was the first study to determine the associations between several chronic conditions, including obesity, asthma, and hyperlipidemia, with clinical outcomes of COVID-19 patients. We also included only studies from the peer-reviewed journals to ensure the validity of conclusions, while some meta-analyses used manuscripts in preprint servers to increase the sample size $(9,15-17)$.

\section{METHODS}

Methods for this systematic review were developed according to the recommendations from the MOOSE statement (18) and PRISMA statement (19) for reporting of systematic review and meta-analysis.

\section{Criteria for Considering Studies for This Review}

Observational studies that focused on adult patients (aged over 16 years) with COVID-19 and investigated the association between chronic diseases and severity, ICU admission, mortality, and ARDS of COVID-19 were included.

The following types of studies were excluded: (1) studies that only included infants, children, and pregnant women; (2) studies that only included decedents (only death patients were enrolled in each group); (3) studies that did not classify patients into different groups by severity, type of hospital wards (i.e., general wards, ICU), mortality, or ARDS; (4) studies that did not have enough statistical information to be extracted from each group of patients; (5) duplicated publication of the same research results, i.e., data from the same hospitals within the same period; and (6) descriptive reviews, systematic review, meta-analysis, opinion, editorial, comments, and conference abstracts without full article publication.

\section{Study Outcomes}

The primary outcome measure was the association between chronic diseases and the severity of COVID-19 patients. Secondary outcomes included the association between chronic diseases and mortality, ICU admission, and ARDS of COVID-19 hospitalized patients. The chronic diseases in our review were hypertension, diabetes, pulmonary disease [chronic obstructive pulmonary disease (COPD), asthma, and unspecified type], cardiovascular disease (coronary heart disease, heart failure, and unspecified type), cerebrovascular disease, hyperlipidemia, obesity, chronic liver disease, chronic renal disease, cerebrovascular disease, and cancer. The association between Charlson comorbidity index and the clinical outcomes of COVID-19 patients was also analyzed.

\section{Search Strategy}

Studies were identified by searching PubMed, Embase, Science Citation Index Expanded (Web of Science), and Cumulative Index to Nursing and Allied Health (CINAHL) Complete. Our search strategy is listed in Appendix 1 in Supplementary Material. References from the retrieved papers were also searched. Studies published between December 1, 2019, and December 31, 2020 were included.

\section{Study Selection and Data Extraction}

In accordance with the defined inclusion criteria, two reviewers independently read the title and abstract of each study retrieved by the search. The reviewers excluded studies that did not meet 
the inclusion criteria. After screening the title and abstract of each study, the full texts of eligible citations were then assessed by the two reviewers independently.

A third reviewer was consulted when the two reviewers could not agree on selecting a study. The reviewers developed a data extraction form and used it to extract data to reflect the characteristics of each included study. If the data from the same hospitals in the same period were published several times, only the paper with the largest sample size was included.

The included studies varied in their classification of disease severity, ranging from mild, moderate, severe, to critical severe. We categorized mild and moderate cases into the non-severe group and severe and critical severe cases into the severe group. We considered the following cases as the ICU groups-ICU admission and requiring invasive mechanical ventilation, and critical cases of illness that were admitted to the ICU.

\section{Risk of Bias Assessment}

We used the tools developed by the Joanna Briggs Institute (JBI) (20-23) to assess the risk of bias of the included studies. The JBI critical appraisal tools for cohort studies, case series, case-control studies, and cross-sectional studies included 11, 10, 10 , and 8 items, respectively. The appraisal tools addressed the internal validity and risk of bias of the study design, particularly confounding, selection, and information bias, in addition to the importance of clear reporting.

\section{Statistical Analysis}

We conducted a meta-analysis when data from more than one study could be combined. We calculated pooled estimates of odds ratio (OR) and $95 \%$ confidence interval (CI) by the generic inverse variance method using STATA 14.2 (STATA Corporation, College Station, TX, USA). We tested the heterogeneity of effective measures using the $I^{2}$ statistic. We defined $I^{2}$ values greater than $50 \%$ as considerable or substantial heterogeneity (24). For data with substantial heterogeneity, a random-effects model using the method developed by DerSimonian and Laird (25) was specified to address heterogeneity among the studies. For data with unsubstantial heterogeneity, a fixed-effects model with the inverse variance method was used to synthesize the data.

For the most prevalent chronic diseases including hypertension, diabetes, COPD, coronary heart disease, cerebrovascular disease, and cancer, we conducted the cumulative meta-analysis according to the season of admission of the patients and the increasing sample size of the included studies within each season. A cumulative meta-analysis is helpful to assess the dynamics of how the summary results change with a newly added study (26). R 4.0.3 (The R Foundation for Statistical Computing, Vienna, Austria) was used to conduct a cumulative meta-analysis.

\section{RESULTS}

\section{Literature Search and Study Selection}

Two hundred and seventeen observational studies (27-243) with 624,986 patients met the inclusion criteria in our systematic review. A PRISMA flowchart summarized our search results and study selection procedure (Figure 1).

\section{Characteristics and Quality of the Included Studies}

Table 1 presents the characteristics of the 217 included studies. The studies were carried out in 26 countries, 83 (38.25\%) of them were performed in multicenters, 123 (56.68\%) were case series, and $82(37.79 \%)$ were cohort studies. The date of admission of the patients was from December 11,2019, to August 1, 2020. Most of the outcome variables were about mortality (48.39\%) and severity (34.10\%). Details of the characteristics are shown in Appendix 2 in Supplementary Material.

The quality assessment score for the case series ranged from 6 to $10(9.13 \pm 0.84)$ with 102 of them $(82.93 \%)$ having a score higher than 8 (10 indicates the best quality). Among the case series, 48 studies (39.02\%) did not indicate a consecutive inclusion of patients, and 45 studies (36.59\%) did not have a complete inclusion of patients.

The score of cohort studies ranged from 6 to $11(10.04$ $\pm 0.92)$ with 62 cohort studies $(75.61 \%)$ having a score more than 9 (11 indicates the best quality). Length of follow-up was not mentioned in 34 cohort studies, and the reasons for losses to follow-up were not described in 6 studies. In addition, we were not sure whether patients across different centers had similar characteristics in relation to exposure (27 studies). Appendix 3 in Supplementary Material presents details of the risk of bias assessment.

\section{Association Between Chronic Diseases and Severity of COVID-19}

We identified 74 studies of COVID-19 severity, involving a total of 32,213 patients and 8,433 cases of severe COVID-19. Among these studies, 65 of them were performed in China, 3 in the USA, and 1 in Bulgaria, Congo, Kuwait, Saudi Arabia, South Korea, and Spain, respectively.

As shown in Table 2, the prevalence of patients with any type of chronic disease in the group of severe COVID-19 was substantially higher than that of the non-severe group (60.71 vs. 31.81\%; OR 3.70, 95\% CI 2.98-4.61). Hypertension (OR 3.05, 95\% 2.60-3.59), diabetes (OR 2.55, 95\% CI 2.14-3.03), COPD (OR 3.91, 95\% CI 3.05-5.02), asthma (OR 1.93, 95\% CI 1.532.42 ), unspecified type of pulmonary disease (OR 2.48, 95\% CI 2.03-3.03), coronary heart disease (OR 2.04, 95\% CI 1.722.42 ), unspecified type of cardiovascular disease (OR 3.01, 95\% CI 2.64-3.43), cerebrovascular disease (OR 2.32, 95\% CI 1.832.94), obesity (OR 2.63, 95\% CI 1.70-4.07), chronic liver disease (OR 1.96, 95\% CI 1.64-2.35), chronic renal disease (OR 2.09, 95\% 1.52-2.87), and cancer (OR 2.33, 95\% 1.90-2.87) were all associated with significantly higher risk of severity among COVID-19 patients. There were only two types of the study chronic diseases (i.e., heart failure and hyperlipidemia) that were not significantly associated with the severity of COVID-19 $(P>$ $0.05)$. However, the prevalence of heart failure or hyperlipidemia was only reported in three studies. 


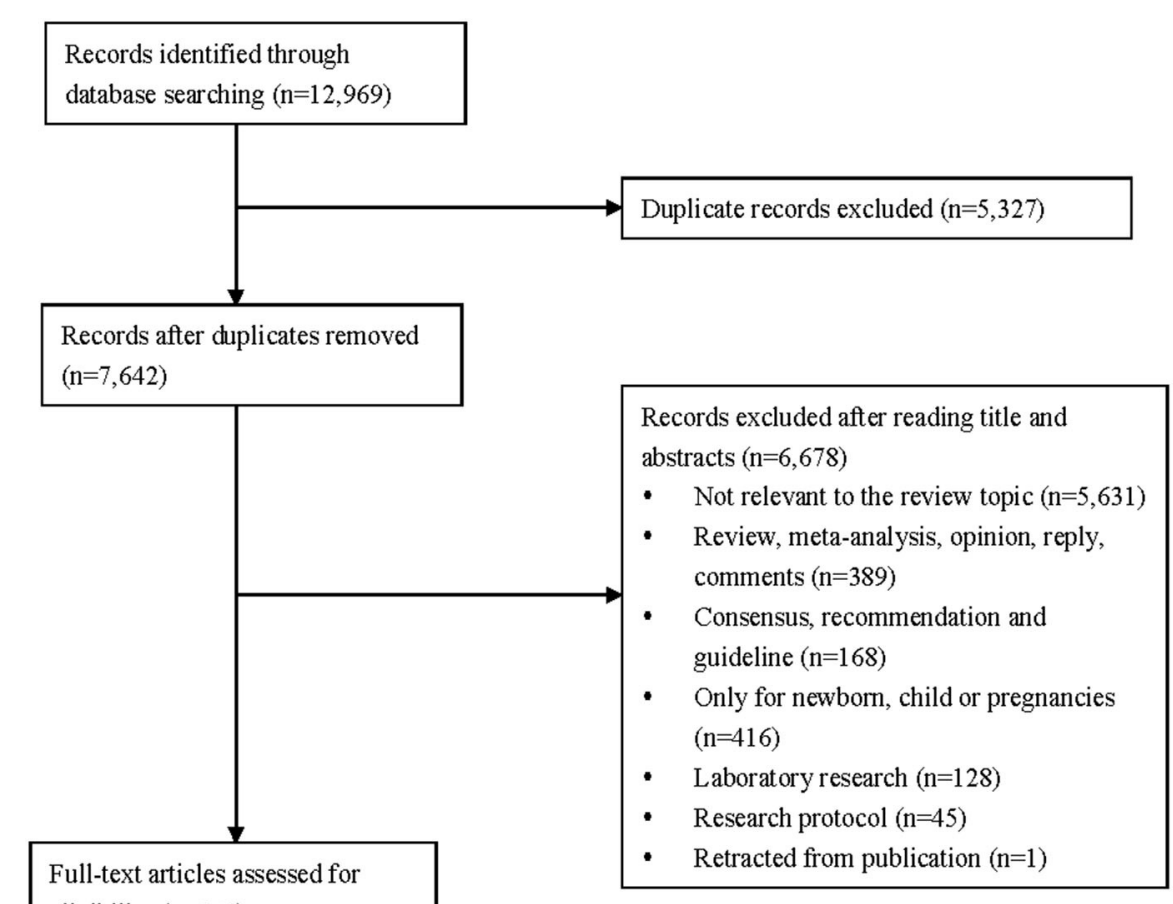

Full text articles excluded $(n=747)$

- Not relevant to the review topic $(n=442)$

- Epidemiological data without comparators $(\mathrm{n}=134)$

- Comparison groups did not meet the inclusion criteria $(n=120)$

- No relevant data to be extracted $(n=41)$

- Duplicate publication from the same data $(n=4)$

- All of the patients enrolled were decadent $(n=6)$

Studies included in analysis $(\mathrm{n}=217)$

FIGURE 1 | Flow diagram of the study selection for inclusion in the systematic review.

Appendix 4 in Supplementary Material presents the forest plots of cumulative meta-analysis for major types of chronic diseases. Subsequent studies increased the precision of the point estimate, and no change occurred in the direction of the effect size.

\section{Association Between Chronic Diseases and Mortality of COVID-19}

We found that 105 studies with a total of 350,522 patients and 68,157 deaths presented data on mortality. Among the studies, 40 of them were carried out in China, 12 in Italy, 11 in the USA, 6 in Iran, 6 in Spain, 4 in India, 4 in the UK, 3 in Brazil, 3 in South Korea, 2 in France, 2 in Mexico, and 1 in Bangladesh, Bolivia, Congo, German, Greece, Ireland, Kuwait, Saudi Arabia,
Switzerland, and Turkey, respectively. We also found two studies that were conducted in multicountries.

As shown in Table 3, 36.49\% of patients who died had at least one type of chronic disease. Hyperlipidemia (52.80\%) was the most common chronic condition among patients who died, followed by hypertension (37.53\%) and unspecified type of cardiovascular disease (28.56\%). Hypertension (OR 2.31, 95\% CI 2.04-2.61), diabetes (OR 1.99, 95\% CI 1.82-2.18), COPD (OR 2.95, 95\% CI 2.48-3.50), unspecified type of pulmonary disease (OR 2.05, 95\% CI 1.83-2.31), coronary heart disease (OR 2.46, 95\% CI 2.14-2.82), heart failure (OR 2.74, 95\% CI 2.21-3.40), unspecified type of cardiovascular disease (OR 2.59, 95\% CI 2.24-3.00), cerebrovascular disease (OR 2.46, 95\% CI 2.08-2.91), hyperlipidemia (OR 1.72, 95\% CI 1.07-2.77), chronic liver disease (OR 1.52, 95\% CI 1.30-1.77), chronic 
TABLE 1 | Characteristics of the included studies.

\begin{tabular}{|c|c|c|}
\hline Characteristics & $\begin{array}{l}\text { Number of } \\
\text { studies }\end{array}$ & $\begin{array}{l}\text { Percentage of the } \\
\text { included studies (\%) }\end{array}$ \\
\hline \multicolumn{3}{|l|}{ Country } \\
\hline China & 111 & 51.15 \\
\hline USA & 21 & 9.68 \\
\hline Italy & 20 & 9.22 \\
\hline South Korea & 7 & 3.23 \\
\hline Spain & 7 & 3.23 \\
\hline Iran & 6 & 2.76 \\
\hline Germany & 5 & 2.30 \\
\hline France & 5 & 2.30 \\
\hline Mexico & 5 & 2.30 \\
\hline India & 4 & 1.84 \\
\hline UK & 4 & 1.84 \\
\hline Brazil & 3 & 1.38 \\
\hline Congo & 2 & 0.92 \\
\hline Kuwait & 2 & 0.92 \\
\hline Saudi Arabia & 2 & 0.92 \\
\hline Bangladesh & 1 & 0.46 \\
\hline Bolivia & 1 & 0.46 \\
\hline Bulgaria & 1 & 0.46 \\
\hline Denmark & 1 & 0.46 \\
\hline Greece & 1 & 0.46 \\
\hline Ireland & 1 & 0.46 \\
\hline Oman & 1 & 0.46 \\
\hline Poland & 1 & 0.46 \\
\hline Qatar & 1 & 0.46 \\
\hline Switzerland & 1 & 0.46 \\
\hline Turkey & 1 & 0.46 \\
\hline Multicountries $^{a}$ & 2 & 0.92 \\
\hline \multicolumn{3}{|l|}{ Data source } \\
\hline Multicenters & 83 & 38.25 \\
\hline Single center & 134 & 61.75 \\
\hline \multicolumn{3}{|l|}{ Type of study } \\
\hline Case series & 123 & 56.68 \\
\hline Retrospective cohort study & 71 & 32.72 \\
\hline Prospective cohort study & 10 & 4.61 \\
\hline Ambispective cohort study & 1 & 0.46 \\
\hline Case-control study & 4 & 1.84 \\
\hline Cross-sectional study & 8 & 3.69 \\
\hline \multicolumn{3}{|l|}{ Type of comparisons ${ }^{b}$} \\
\hline Severe vs. non-severe & 74 & 34.10 \\
\hline Death vs. survival & 105 & 48.39 \\
\hline ICU vs. non-ICU & 53 & 24.42 \\
\hline ARDS vs. non-ARDS & 6 & 2.76 \\
\hline
\end{tabular}

${ }^{a}$ One was carried out in Europe, and the other was conducted in China, Europe, and North America.

${ }^{b}$ Seventeen studies had two types of comparisons. Two studies had three types of comparisons.

renal disease (OR 2.85, 95\% CI 2.44-3.33), and cancer (OR $2.11,95 \%$ CI 1.85-2.42) were associated with a higher risk of mortality.
We found no significant correlation between obesity (OR 1.19, 95\% CI 0.94-1.51) and death. We also did the subgroup analysis for morbid obesity $\left(\mathrm{BMI} \geq 40 \mathrm{~kg} / \mathrm{m}^{2}\right)$, and the results were not statistically significant (OR 0.98, 95\% CI 0.80-1.20). Our metaanalysis showed that asthma was associated with a reduced risk of mortality (OR 0.74, 95\% CI 0.68-0.80). The Charlson index score equals to 0 seemed to be a protective factor for mortality (OR 0.31 , 95\% CI $0.18-0.51$ ), while a score $\geq 2$ might be consistent with the higher likelihood of death (OR 4.22, 95\% CI 2.56-6.96).

The cumulative meta-analysis showed that the sample size increased; the CI for hypertension, diabetes, COPD, coronary heart disease, and cancer became increasingly narrower; and statistical significance was more common (Appendix 4 in Supplementary Material). However, the subgroup of cerebrovascular disease with the admission date of patients in summer was not significant $(P>0.05)$, probably due to only two studies were included.

\section{Association Between Chronic Diseases and ICU Admission of COVID-19}

Fifty-three studies involving a total of 260,465 patients and 12,233 cases of ICU admission were included. Of these studies, 14 were conducted in China; 9 in the USA; 6 in Italy; 4 in South Korea; 3 in France, Germany, and Mexico, respectively; 2 in Kuwait; and 1 in Denmark, India, Iran, Oman, Poland, Qatar, Saudi Arabia, Spain, and Turkey, respectively.

We found that $73.62 \%$ of the ICU patients had at least one type of chronic disease, which was significantly higher than that in the non-ICU group (OR 2.82, 95\% CI 2.23-3.56) (Table 4). Hypertension (OR 2.24, 95\% CI 1.90-2.63), diabetes (OR 2.50, 95\% CI 2.18-2.87), COPD (OR 2.76, 95\% CI 1.993.82 ), unspecified type of pulmonary disease (OR 1.40 , $95 \%$ CI 1.26-1.56), coronary heart disease (OR 2.16, 95\% CI $1.56-$ 2.99), heart failure (OR 1.80, 95\% CI 1.44-2.55), unspecified type of cardiovascular disease (OR 2.38, 95\% CI 1.92-2.96), hyperlipidemia (OR 1.53, 95\% CI 1.22-1.93), obesity (OR 1.86, 95\% CI 1.49-2.31), chronic renal disease (OR 2.25, 95\% CI 1.73-2.94), and cancer (OR 1.57, 95\% CI 1.39-1.77) were significant predictive factors for admission to ICU. On the other hand, asthma and chronic liver disease were not significantly associated with ICU admission $(P>0.05)$. The association between cerebrovascular disease and ICU admission was not very obvious $(P=0.048)$.

The cumulative meta-analysis showed that the statistical significance of hypertension, diabetes, COPD, coronary heart disease, and cancer had the tendency of becoming evident with increasing sample size (Appendix 4 in Supplementary Material).

\section{Association Between Chronic Diseases and ARDS of COVID-19}

Six studies involving a total of 2,128 patients and 635 cases of ARDS admission were included. Two of them were conducted in China, two in Italy, and 1 in Germany and the USA, respectively.

We found a significant association between hypertension (OR 2.17, 95\% CI 1.78-2.66), diabetes (OR 2.32, 95\% CI 1.703.17), coronary heart disease (OR 1.96, 95\% CI 1.32-2.92), 
TABLE 2 | Associations between chronic diseases and severity of COVID-19.

\begin{tabular}{|c|c|c|c|c|c|c|c|c|}
\hline Chronic diseases & $\begin{array}{l}\text { Number of } \\
\text { included } \\
\text { studies }\end{array}$ & $\begin{array}{l}\text { Number of } \\
\text { severe } \\
\text { Covid-19 } \\
\text { patients }\end{array}$ & $\begin{array}{c}\text { Number of } \\
\text { non-severe } \\
\text { COVID-19 } \\
\text { patients }\end{array}$ & $\begin{array}{c}\text { Prevalence } \\
\text { in the severe } \\
\text { group (\%) }\end{array}$ & $\begin{array}{l}\text { Prevalence } \\
\text { in the } \\
\text { non-severe } \\
\text { group (\%) }\end{array}$ & $I^{2}$ & $\begin{array}{c}\text { Pooled OR } \\
\text { (95\% Cl) }\end{array}$ & $P$-value \\
\hline Hypertension & 67 & 6,453 & 18,352 & 42.97 & 20.04 & 76.7 & $3.05(2.60-3.59)$ & 0.000 \\
\hline Diabetes & 70 & 7,184 & 21,106 & 20.98 & 10.78 & 67.7 & $2.55(2.14-3.03)$ & 0.000 \\
\hline \multicolumn{9}{|l|}{ Pulmonary diseases } \\
\hline Asthma (conclusion changed) & 9 & 997 & 3,671 & 14.24 & 13.54 & 0.0 & $1.93(1.53-2.42)$ & 0.000 \\
\hline Unspecified type ${ }^{a}$ & 20 & 1,720 & 5,917 & 18.84 & 16.48 & 5.7 & $2.48(2.03-3.03)$ & 0.000 \\
\hline \multicolumn{9}{|l|}{ Cardiovascular diseases } \\
\hline Coronary heart disease & 20 & 3,184 & 9,133 & 9.58 & 4.03 & 34.7 & $2.04(1.72-2.42)$ & 0.000 \\
\hline Heart failure & 3 & 83 & 100 & 14.46 & 14.00 & 57.6 & $1.74(0.26-11.45)$ & 0.567 \\
\hline Unspecified type ${ }^{a}$ & 32 & 3,052 & 9,158 & 21.04 & 8.83 & 45.9 & $3.01(2.64-3.43)$ & 0.000 \\
\hline Chronic liver disease & 27 & 4,176 & 12,622 & 8.19 & 9.55 & 26.4 & $1.96(1.64-2.35)$ & 0.000 \\
\hline Chronic renal disease & 33 & 5,198 & 15,388 & 4.66 & 2.56 & 50.2 & $2.09(1.52-2.87)$ & 0.000 \\
\hline Cancer & 40 & 3,507 & 10,917 & 5.47 & 2.56 & 6.6 & $2.33(1.90-2.87)$ & 0.000 \\
\hline Any types of chronic disease ${ }^{a}$ & 33 & 3,118 & 8,206 & 60.71 & 31.81 & 71.4 & $3.70(2.98-4.61)$ & 0.000 \\
\hline
\end{tabular}

a The included studies did not mention the specific types of disease in this category.

TABLE 3 | Associations between chronic diseases and mortality of COVID-19.

\begin{tabular}{|c|c|c|c|c|c|c|c|c|}
\hline Chronic diseases & $\begin{array}{c}\text { Number of } \\
\text { included } \\
\text { studies }\end{array}$ & $\begin{array}{c}\text { Number of } \\
\text { COVID-19 } \\
\text { deaths }\end{array}$ & $\begin{array}{l}\text { Number of } \\
\text { COVID-19 } \\
\text { survivors }\end{array}$ & $\begin{array}{c}\text { Prevalence } \\
\text { in the death } \\
\text { group (\%) }\end{array}$ & $\begin{array}{c}\text { Prevalence } \\
\text { in the } \\
\text { survival } \\
\text { group (\%) }\end{array}$ & $I^{2}$ & $\begin{array}{c}\text { Pooled OR } \\
(95 \% \mathrm{Cl})\end{array}$ & $P$-value \\
\hline Hypertension & 96 & 49,072 & 205,854 & 37.53 & 26.86 & 92.2 & $2.31(2.04-2.61)$ & 0.000 \\
\hline Diabetes & 105 & 57,121 & 250,467 & 22.34 & 15.29 & 84.8 & $1.99(1.82-2.18)$ & 0.000 \\
\hline \multicolumn{9}{|l|}{ Pulmonary diseases } \\
\hline COPD & 54 & 13,013 & 52,915 & 13.18 & 6.93 & 73.0 & $2.95(2.48-3.50)$ & 0.000 \\
\hline Asthma & 16 & 11,026 & 36,444 & 8.51 & 8.50 & 0.0 & $0.74(0.68-0.80)$ & 0.000 \\
\hline Unspecified type ${ }^{a}$ & 29 & 19,961 & 120,999 & 21.91 & 13.72 & 63.1 & $2.05(1.83-2.31)$ & 0.000 \\
\hline \multicolumn{9}{|l|}{ Cardiovascular diseases } \\
\hline Coronary heart disease & 35 & 9,533 & 36,597 & 22.36 & 11.73 & 63.1 & $2.46(2.14-2.82)$ & 0.000 \\
\hline Heart failure & 24 & 18,504 & 125,276 & 21.17 & 6.99 & 92.9 & $2.74(2.21-3.40)$ & 0.000 \\
\hline Unspecified type ${ }^{a}$ & 52 & 16,043 & 52,536 & 28.56 & 12.15 & 79.3 & $2.59(2.24-3.00)$ & 0.000 \\
\hline Cerebrovascular disease & 40 & 16,889 & 122,332 & 11.82 & 4.23 & 69.7 & $2.46(2.08-2.91)$ & 0.000 \\
\hline Hyperlipidemia & 6 & 9,875 & 69,330 & 52.80 & 29.94 & 97.8 & $1.72(1.07-2.77)$ & 0.000 \\
\hline Obesity & 27 & 35,778 & 119,672 & 7.00 & 8.77 & 93.0 & $1.19(0.94-1.51)$ & 0.147 \\
\hline Morbid obesity & 3 & 1,556 & 3,975 & 9.51 & 10.06 & 0.0 & $0.98(0.80-1.20)$ & 0.858 \\
\hline Chronic liver disease & 27 & 9,988 & 26,493 & 2.93 & 2.30 & 32.3 & $1.52(1.30-1.77)$ & 0.000 \\
\hline Chronic renal disease & 60 & 23,024 & 82,836 & 14.11 & 5.68 & 78.3 & $2.85(2.44-3.33)$ & 0.000 \\
\hline Cancer & 65 & 26,704 & 142,413 & 11.58 & 5.66 & 70.5 & $2.11(1.85-2.42)$ & 0.000 \\
\hline \multicolumn{9}{|l|}{ Charlson index } \\
\hline 0 & 3 & 34,308 & 129,484 & 78.54 & 83.17 & 99.3 & $0.31(0.18-0.51)$ & 0.000 \\
\hline 1 & 2 & 23,103 & 97,763 & 4.79 & 7.06 & 98.1 & $1.25(0.67-2.33)$ & 0.481 \\
\hline$\geq 2$ & 3 & 34,308 & 129,484 & 20.29 & 10.95 & 98.7 & $4.22(2.56-6.96)$ & 0.000 \\
\hline Any type of chronic diseases ${ }^{a}$ & 43 & 35,905 & 113,002 & 36.49 & 24.88 & 88.8 & $3.11(2.64-3.65)$ & 0.000 \\
\hline
\end{tabular}

a The included studies did not mention the specific type of disease in this category. 
TABLE 4 | Associations between chronic diseases and ICU admission of COVID-19.

\begin{tabular}{|c|c|c|c|c|c|c|c|c|}
\hline Chronic diseases & $\begin{array}{c}\text { Number of } \\
\text { included } \\
\text { studies }\end{array}$ & $\begin{array}{c}\text { Number of } \\
\text { ICU } \\
\text { COVID-19 } \\
\text { patients }\end{array}$ & $\begin{array}{c}\text { Number of } \\
\text { non-ICU } \\
\text { COVID-19 } \\
\text { patients }\end{array}$ & $\begin{array}{c}\text { Prevalence } \\
\text { in the ICU } \\
\text { group (\%) }\end{array}$ & $\begin{array}{l}\text { Prevalence } \\
\text { in the } \\
\text { non-ICU } \\
\text { group }(\%)\end{array}$ & $I^{2}$ & $\begin{array}{c}\text { Pooled OR } \\
\text { (95\% Cl) }\end{array}$ & $P$-value \\
\hline Hypertension & 50 & 12,062 & 247,158 & 47.78 & 24.72 & 87.1 & $2.24(1.90-2.63)$ & 0.000 \\
\hline Diabetes & 51 & 12,188 & 247,334 & 37.27 & 17.28 & 79.6 & $2.50(2.18-2.87)$ & 0.000 \\
\hline \multicolumn{9}{|l|}{ Pulmonary disease } \\
\hline COPD & 25 & 7,648 & 223,993 & 6.85 & 2.43 & 69.7 & $2.76(1.99-3.82)$ & 0.000 \\
\hline Asthma & 11 & 7,070 & 220,430 & 3.92 & 3.02 & 26.1 & 1.07 (0.94-1.22) & 0.280 \\
\hline Unspecified type ${ }^{a}$ & 14 & 2,690 & 18,052 & 20.86 & 16.62 & 0.0 & $1.40(1.26-1.56)$ & 0.000 \\
\hline \multicolumn{9}{|l|}{ Cardiovascular disease } \\
\hline Coronary heart disease & 20 & 2,743 & 19,716 & 24.32 & 14.09 & 79.9 & 2.16 (1.56-2.99) & 0.000 \\
\hline Heart failure & 11 & 3,969 & 24,536 & 20.58 & 11.81 & 62.7 & $1.80(1.44-2.25)$ & 0.000 \\
\hline Unspecified type ${ }^{a}$ & 28 & 7,801 & 212,550 & 17.13 & 3.00 & 54.8 & $2.38(1.92-2.96)$ & 0.000 \\
\hline Cerebrovascular disease & 19 & 2,587 & 20,957 & 10.86 & 4.67 & 80.7 & $1.66(1.00-2.75)$ & 0.048 \\
\hline Hyperlipidemia & 4 & 1,713 & 11,354 & 54.64 & 51.77 & 53.2 & $1.53(1.22-1.93)$ & 0.000 \\
\hline Obesity & 19 & 10,016 & 232,568 & 30.65 & 20.52 & 89.4 & $1.86(1.49-2.31)$ & 0.000 \\
\hline Chronic liver disease & 16 & 889 & 6,699 & 2.92 & 1.97 & 0.0 & $1.48(0.95-2.29)$ & 0.082 \\
\hline Chronic renal disease & 31 & 10,550 & 237,131 & 11.54 & 3.63 & 82.8 & $2.25(1.73-2.94)$ & 0.000 \\
\hline Cancer & 30 & 3,286 & 21,949 & 14.39 & 11.93 & 34.2 & $1.57(1.39-1.77)$ & 0.000 \\
\hline Any type of chronic disease ${ }^{a}$ & 22 & 8,329 & 223,276 & 73.62 & 47.79 & 81.0 & $2.82(2.23-3.56)$ & 0.000 \\
\hline
\end{tabular}

a The included studies did not mention the specific type of disease in this category.

TABLE 5 | Associations between chronic diseases and ARDS of COVID-19.

\begin{tabular}{|c|c|c|c|c|c|c|c|c|}
\hline Chronic diseases $^{a}$ & $\begin{array}{c}\text { Number of } \\
\text { included } \\
\text { studies }\end{array}$ & $\begin{array}{c}\text { Number of } \\
\text { COVID-19 } \\
\text { patients } \\
\text { with ARDS }\end{array}$ & $\begin{array}{c}\text { Number of } \\
\text { COVID-19 } \\
\text { patients } \\
\text { without } \\
\text { ARDS }\end{array}$ & $\begin{array}{c}\text { Prevalence } \\
\text { in the ARDS } \\
\text { group (\%) }\end{array}$ & $\begin{array}{c}\text { Prevalence } \\
\text { in the } \\
\text { non-ARDS } \\
\text { group }(\%)\end{array}$ & $I^{2}$ & $\begin{array}{c}\text { Pooled OR } \\
(95 \% \mathrm{Cl})\end{array}$ & $P$-value \\
\hline Hypertension & 6 & 635 & 1,493 & 58.11 & 38.71 & 0.0 & $2.17(1.78-2.66)$ & 0.000 \\
\hline Diabetes & 6 & 635 & 1,493 & 16.54 & 9.58 & 21.5 & $2.32(1.70-3.17)$ & 0.000 \\
\hline COPD & 4 & 499 & 986 & 15.23 & 8.01 & 68.4 & $1.35(0.54-3.37)$ & 0.516 \\
\hline \multicolumn{9}{|l|}{ Cardiovascular disease } \\
\hline Coronary heart disease & 2 & 449 & 856 & 12.03 & 6.43 & 0.0 & $1.96(1.32-2.92)$ & 0.001 \\
\hline Heart failure & 2 & 449 & 856 & 10.69 & 5.26 & 58.4 & $1.85(0.834-4.11)$ & 0.130 \\
\hline Unspecified type ${ }^{b}$ & 3 & 162 & 611 & 10.49 & 7.20 & 0.0 & $2.35(1.24-4.47)$ & 0.009 \\
\hline Cerebrovascular disease & 3 & 473 & 882 & 12.69 & 6.35 & 71.5 & $1.41(0.46-4.30)$ & 0.546 \\
\hline Obesity & 4 & 525 & 1,272 & 28.95 & 12.42 & 70.7 & $2.25(1.18-4.28)$ & 0.014 \\
\hline Chronic renal disease & 4 & 499 & 986 & 12.63 & 7.71 & 14.1 & 1.63 (1.14-2.33) & 0.008 \\
\hline
\end{tabular}

a Only data for these chronic diseases were available to conduct meta-analyses. ${ }^{b}$ The included studies did not mention the specific type of disease in this category.

unspecified type of cardiovascular disease (OR 2.35, 95\% CI $1.24-4.47$ ), obesity (OR $2.25,95 \%$ CI $1.18-4.28$ ), chronic renal disease (OR 1.63, 95\% CI 1.14-2.33), and occurrence of ARDS (Table 5). COPD, heart failure, and cerebrovascular disease were not significantly correlated with the risk of ARDS $(P>0.05)$.

\section{DISCUSSION}

Given the ongoing COVID-19 pandemic and the consequent global healthcare crisis, there is an urgent need to better understand risk factors for symptom deterioration and identify the vulnerable populations at higher risk for COVID-19 mortality. Our meta-analysis aimed to meet the need by examining global evidence, including 217 studies from 26 countries with 624,986 COVID-19 patients. Compared with a prior meta-analysis that showed that among COVID-19 patients, $20.3 \%$ required ICU admission and $32.8 \%$ had ARDS (244), our analysis provided further data on the association between chronic diseases and the different clinical prognoses of COVID-19 patients. According to our findings, COVID-19 
patients with chronic diseases were more likely to have severe symptoms, ICU admissions, and an increased risk of mortality.

On the contrary, a meta-analysis found that pre-existing chronic conditions were not correlated with COVID-19 mortality (OR 2.09, 95\% CI 0.26 to 16.67) (12). However, the conclusion of that meta-analysis was not reliable due to the fact that it only included three studies with a small sample size (453). In comparison, our meta-analysis had a much large sample size and identified the significant associations between a variety of chronic conditions and COVID-19 mortality, such as hypertension, diabetes, COPD, unspecified type of pulmonary disease, coronary heart disease, heart failure, unspecified type of cardiovascular disease, cerebrovascular disease, hyperlipidemia, chronic liver disease, chronic renal disease, and cancer.

We found that among COVID-19 patients, hypertension was a common comorbidity and was associated with COVID-19 severity, ICU admission, ARDS, and mortality. We found that COPD was the strongest predictive comorbidity for COVID19 severity, ICU admission, and mortality, a finding that is consistent with prior research results, confirming that COPD patients are particularly vulnerable for very severe or critical COVID-19 cases (6).

Whereas, the published COVID-19 systematic reviews used the term "cardiovascular disease" generally (11, 13, 245), merely merged different types of cardiovascular diseases into a single measure, or only used the data from "unspecified type of cardiovascular diseases" as the outcome $(6,11,13)$, we categorized cardiovascular diseases into three groupscoronary heart disease, heart failure, and unspecified type of cardiovascular diseases-to provide specific evidence for decision-makers. We found that coronary heart disease was a potential risk factor for the severity, ICU admission, mortality, and ARDS of COVID-19, while heart failure could increase the probability of ICU admission and mortality.

According to our results, cerebrovascular disease was an important comorbidity for COVID-19 mortality. We also identified cerebrovascular disease as a risk factor for severity of COVID-19 patients, which was consistent with other metaanalyses $(14,245)$. However, we found that there was a weak association between cerebrovascular disease and the risk of ICU admission, a finding that was different from a meta-analysis showing that cardio-cerebrovascular diseases were about 3-fold higher in ICU patients than in their non-ICU counterparts (17). However, only six studies were included in that metaanalysis, and its method was problematic as it calculated relative risk despite the fact that it included retrospective studies. Furthermore, cardiovascular disease and cerebrovascular disease were combined into a single outcome measure in the previous meta-analysis.

Asthma is a chronic disease of the air passages of the lungs which inflames and narrows them. Both its prevalence and mortality increased in recent decades, accounting for 272.68 million cases $(3.57 \%)$ and 0.49 million deaths $(0.006 \%)$ in the year 2017 (246). A multicenter retrospective study in 10 US hospitals found that asthma did not lead to an increased risk of hospitalization (RR 0.96, 95\% CI 0.77-1.19) for COVID-19 patients after adjusting for age, sex, gender, and comorbidities (247). However, we found that asthma was associated with the severity of COVID-19 but tended to become a protective factor to reduce mortality risk. On the other hand, a published metaanalysis demonstrated that asthma patients were not predisposed to severe COVID-19 infections (248). It should be noted that the meta-analysis searched for articles published from January 1 , 2020, to August 28, 2020, which was even shorter than our study, and only five studies were included in that meta-analysis.

The prevalence of obesity in many countries has been increasing rapidly in recent decades. We found that obese patients were at a higher risk of developing severe COVID-19 symptoms. However, the association between obesity (BMI $\geq 28$ or $30 \mathrm{~kg} / \mathrm{m}^{2}$ ) and mortality was not statistically significant. We did not find a significant relationship between morbid obesity $\left(\mathrm{BMI} \geq 40 \mathrm{~kg} / \mathrm{m}^{2}\right)$ and mortality.

Hyperlipidemia involves an imbalance of cholesterol levels, including low-density lipoprotein cholesterol (LDL-C) and highdensity lipoprotein cholesterol (HDL-C) in the blood. It has become common in many countries (249), especially in the USA where low HDL-C among adults aged 20 and over was $17.2 \%$ (250) and roughly $53 \%$ of adults had elevated LDL-C levels (251). Our results showed that hyperlipidemia was associated with increased ICU admission and mortality of COVID-19 patients.

A meta-analysis revealed an insignificant correlation between the increased risk of severe COVID-19 and liver disease, cancer, or renal disease (245). The insignificant results were probably due to the small number of studies included in the analysis-only five studies were included and all of them were from China. In contrast, our large sample size from multiple countries enabled us to find that those COVID-19 patients with chronic liver disease, cancer, or chronic renal disease were more likely to become severe cases and had a higher risk of mortality.

Our results emphasize the need for enhanced vigilance, priority for detection and testing, and aggressive COVID-19 therapy for patients with chronic diseases. Given our findings that COVID-19 patients with various chronic diseases were more likely to experience severe symptoms and ICU admissions and faced a higher risk of mortality, policymakers across different countries need to target patients with chronic diseases as a priority of their strategies to combat the COVID-19 pandemic. In particular, measures should be taken to protect the vulnerable groups with specific types of chronic disease, such as hypertension, diabetes, cardiovascular disease, and hyperlipidemia, each of which has a high prevalence in the general population.

For some of the less common chronic conditions, a targeted and intensive health protection strategy is also warranted. For example, although COPD is a less common condition among the general population, our analysis indicated that it is strongly associated with COVID-19 severity, ICU admission, and mortality. We also found that cerebrovascular disease, a less common condition that is the leading cause of serious long-term disability, was a significant comorbidity predicting mortality in COVID-19 patients. Thus, patients with COPD and/or cerebrovascular diseases 
should receive special attention from both policymakers and healthcare professionals.

Finally, our analysis suggested that more adequately powered studies should be conducted to investigate how the severity and mortality of COVID-19 are associated with morbid obesity and hyperlipidemia, and a composite measure of comorbidity such as the Charlson comorbidity index must be utilized. The risk factors for ARDS in patients with severe COVID-19 are also worthy of further analysis in the future.

The results of our systematic review should be interpreted in the context of its limitations. First, we did not include studies that only analyzed children, pregnancies, and healthcare professionals in order to ensure the homogeneity and representativeness of the general population. The existing systematic reviews found that children seemed to have a milder disease course and better prognosis than adults (252) and that vertical transmission of COVID-19 from pregnancies to newborns could not be ruled out (253). Second, there was a limited sample size on risk factors for ARDS, and future observational studies are still needed on this topic. Third, the predictive value of concurrent multiple chronic diseases for the prognosis of COVID-19 patients remains unclear. Fourth, we were unable to conduct subgroup analysis according to community dwellings and institutionalized individuals due to a lack of data from the included studies. The association between chronic diseases and severity of COVID-19 should be further analyzed in community care and institutional care, respectively. Finally, further observational studies and meta-analyses are still needed to explore the impacts of chronic diseases on the severity and mortality in later waves of the COVID-19 pandemic.

\section{DATA AVAILABILITY STATEMENT}

The original contributions presented in the study are included in the article/Supplementary Material, further inquiries can be directed to the corresponding author.

\section{REFERENCES}

1. World Health Organization. Statement on the Second Meeting of the International Health Regulations (2005) Emergency Committee Regarding the Outbreak of Novel Coronavirus (2019-nCoV). (2020). Available online at: https://www.who.int/news-room/detail/30-01-2020-statement-onthe-second-meeting-of-the-international-health-regulations-(2005)emergency-committee-regarding-the-outbreak-of-novel-coronavirus(2019-ncov) (accessed June 2, 2020).

2. World Health Organization. Coronavirus disease (COVID-19) Situation Report-157. (2020). Available online at: https://www.who.int/docs/defaultsource/coronaviruse/situation-reports/20200625-covid-19-sitrep-157.pdf? sfvrsn=423f4a82_2 (accessed June 2, 2020).

3. Stevens MP, Doll M, Pryor R, Godbout E, Cooper K, Bearman G. Impact of COVID-19 on traditional healthcare-associated infection prevention efforts. Infect Control Hosp Epidemiol. (2020) 41:946-7. doi: 10.1017/ice.20 20.141

4. Wu Z, McGoogan JM. Characteristics of and important lessons from the coronavirus disease 2019 (COVID-19) outbreak in China: summary of a report of 72314 cases from the chinese center for disease control and prevention. JAMA. (2020) 323:1239-42. doi: 10.1001/jama.2020.2648

\section{AUTHOR CONTRIBUTIONS}

HY and JG designed the protocol. JG, XC, and CL performed the literature search and screening. $\mathrm{XYu}, \mathrm{HB}, \mathrm{ZF}, \mathrm{JZ}$, and $\mathrm{XC}$ extracted the data and did the quality assessment. JG and YC checked the data. XYuan took part in the interpretation of the data. JG and HY contributed to the meta-analysis and interpretation of the results and drafted the manuscript. All authors contributed to the article and approved the submitted version.

\section{FUNDING}

This work was supported by National Natural Science Foundation of China (Grant No. 71603138), Jiangsu Overseas Visiting Scholar Program for University Prominent Young \& Middle-aged Teachers and Presidents, and Primary Healthcare Research Project in Nantong (Grant No. 2020JCC003). The funders had no role in the design, literature search, data extraction, statistical analysis, data interpretation, or writing of the manuscript.

\section{ACKNOWLEDGMENTS}

At the time of drafting the manuscript, JG was a fellow at the Fellowship in Health Policy and Insurance Research, Department of Population Medicine, Harvard Medical School and Harvard Pilgrim Healthcare Institute. We sincerely acknowledge the comments and suggestions from the reviewers.

\section{SUPPLEMENTARY MATERIAL}

The Supplementary Material for this article can be found online at: https://www.frontiersin.org/articles/10.3389/fmed. 2021.588013/full\#supplementary-material

5. Emami A, Javanmardi F, Pirbonyeh N, Akbari A. Prevalence of underlying diseases in hospitalized patients with COVID-19: a systematic review and meta-analysis. Arch Acad Emergency Med. (2020) 8:e35. doi: 10.22037/aaem.v8i1.600

6. Jain V, Yuan JM. Predictive symptoms and comorbidities for severe COVID19 and intensive care unit admission: a systematic review and meta-analysis. Int J Public Health. (2020) 65:533-46. doi: 10.1007/s00038-020-01390-7

7. Li X, Guan B, Su T, Liu W, Chen M, Bin Waleed K, et al. Impact of cardiovascular disease and cardiac injury on in-hospital mortality in patients with COVID-19: a systematic review and meta-analysis. Heart. (2020) 106:1142-7. doi: 10.1136/heartjnl-2020-317062

8. Yang J, Zheng Y, Gou X, Pu K, Chen Z, Guo Q, et al. Prevalence of comorbidities and its effects in patients infected with SARS-CoV-2: a systematic review and meta-analysis. Int J Infect Dis. (2020) 94:91-5. doi: 10.1016/j.ijid.2020.03.017

9. Zhang J, Wu J, Sun X, Xue H, Shao J, Cai W, et al. Association of hypertension with the severity and fatality of SARS-CoV-2 infection: a meta-analysis. Epidemiol Infect. (2020) 148:e106. doi: 10.1017/s095026882000117x

10. Zhao Q, Meng M, Kumar R, Wu Y, Huang J, Lian N, et al. The impact of COPD and smoking history on the severity of COVID-19: a systemic review and meta-analysis. J Med Virol. (2020) 92:1915-21. doi: 10.1002/jmv.25889 
11. Zheng Z, Peng F, Xu B, Zhao J, Liu H, Peng J, et al. Risk factors of critical \& mortal COVID-19 cases: a systematic literature review and meta-analysis. J Infect. (2020) 81:e16-25. doi: 10.1016/j.jinf.2020.04.021

12. Liu $\mathrm{H}$, Chen $\mathrm{S}$, Liu $\mathrm{M}$, Nie $\mathrm{H}, \mathrm{Lu} \mathrm{H}$. Comorbid chronic diseases are strongly correlated with disease severity among COVID-19 patients: a systematic review and meta-analysis. Aging Dis. (2020) 11:668-78. doi: 10.14336/ad.2020.0502

13. Parohan M, Yaghoubi S, Seraji A, Javanbakht MH, Sarraf P, Djalali M. Risk factors for mortality in patients with Coronavirus disease 2019 (COVID19) infection: a systematic review and meta-analysis of observational studies. Aging Male. (2020) 23:1416-24. doi: 10.1080/13685538.2020.1774748

14. Tian W, Jiang W, Yao J, Nicholson CJ, Li RH, Sigurslid HH, et al. Predictors of mortality in hospitalized COVID-19 patients: a systematic review and meta-analysis. J Med Virol. (2020) 92:1875-83. doi: 10.1002/jmv.26050

15. Pranata R, Lim MA, Huang I, Raharjo SB, Lukito AA. Hypertension is associated with increased mortality and severity of disease in COVID19 pneumonia: a systematic review, meta-analysis and meta-regression. J Renin Angiotensin Aldosterone Syst. (2020) 21:1470320320926899. doi: 10.1177/1470320320926899

16. Zhu J, Ji P, Pang J, Zhong Z, Li H, He C, et al. Clinical characteristics of 3062 COVID-19 patients: a meta-analysis. J Med Virol. (2020) 92:1902-14. doi: 10.1002/jmv. 25884

17. Jiang SW, Gao H, Wu L, Wang GW, Cen FL, Li JX, et al. [Clinical feature changes of a COVID-19 patient from mild to critical condition and cardiopulmonary pathological results]. Zhonghua Xin Xue Guan Bing Za Zhi. (2020) 48:580-6. doi: 10.3760/cma.j.cn112148-20200304-00155

18. Stroup DF, Berlin JA, Morton SC, Olkin I, Williamson GD, Rennie D, et al. Meta-analysis of observational studies in epidemiology: a proposal for reporting. Meta-analysis of observational studies in epidemiology (MOOSE) group. JAMA. (2000) 283:2008-12. doi: 10.1001/jama.283.15.2008

19. Moher D, Liberati A, Tetzlaff J, Altman DG. Preferred reporting items for systematic reviews and meta-analyses: the PRISMA statement. BMJ. (2009) 339:b2535. doi: 10.1136/bmj.b2535

20. The Joanna Briggs Institute. Critical Appraisal Tools for Use in JBI Systematic Reviews: Checklist for Cohort Studies. (2020). Available online at: http:// joannabriggs.org/research/critical-appraisal-tools.html (accessed June 16, 2021).

21. The Joanna Briggs Institute. Critical Appraisal Tools for Use in JBI Systematic Reviews: Checklist for Case Series. (2020). Available online at: http:// joannabriggs.org/research/critical-appraisal-tools.html. (accessed June 16, 2021).

22. The Joanna Briggs Institute. Critical Appraisal Tools for Use in JBI Systematic Reviews: Checklist for Case-Control Studies. (2020). Available online at: http:// joannabriggs.org/research/critical-appraisal-tools.html. (accessed June 16, 2021).

23. The Joanna Briggs Institute. Critical Appraisal Tools for Use in JBI Systematic Reviews: Checklist for Analytical Cross Sectional Studies. (2020). Available online at: http://joannabriggs.org/research/critical-appraisal-tools. html. (accessed June 16, 2021).

24. Higgins J, Wells G. Cochrane Handbook for Systematic Reviews of Interventions: Cochrane Collaboration. (2019). Available online at: https:// training.cochrane.org/handbook/current. (accessed June 16, 2020).

25. DerSimonian R, Laird N. Meta-analysis in clinical trials. Controlled Clin Trials. (1986) 7:177-88. doi: 10.1016/0197-2456(86)90046-2

26. Feng H, Zhao Y, Jing T, Ma J, Zhao Y, Zhang J, et al. Traditional and cumulative meta-analysis: Chemoradiotherapy followed by surgery versus surgery alone for resectable esophageal carcinoma. Mol Clin Oncol. (2018) 8:342-51. doi: 10.3892/mco.2017.1534

27. Abohamr SI, Abazid RM, Aldossari MA, Amer HA, Badhawi OS, Aljunaidi $\mathrm{OM}$, et al. Clinical characteristics and in-hospital mortality of COVID19 adult patients in Saudi Arabia. Saudi Med J. (2020) 41:1217-26. doi: 10.15537/smj.2020.11.25495

28. Aggarwal S, Garcia-Telles N, Aggarwal G, Lavie C, Lippi G, Henry BM. Clinical features, laboratory characteristics, and outcomes of patients hospitalized with coronavirus disease 2019 (COVID-19): early report from the United States. Diagnosis. (2020) 7:91-6. doi: 10.1515/dx-20200046
29. Ali S, H DA, Arash M, Alireza A, Mehdi K, Saman H, et al. Novel coronavirus disease 2019: predicting prognosis by using a computed tomography severity score and clinicolaboratory data. Polish Arch Intern Med. (2020) 130:629-34. doi: 10.20452/pamw.15422

30. Allameh SF, Nemati S, Ghalehtaki R, Mohammadnejad E, Aghili SM, Khajavirad N, et al. Clinical characteristics and outcomes of 905 COVID-19 patients admitted to imam khomeini hospital complex in the capital city of Tehran, Iran. Arch Iran Med. (2020) 23:766-75. doi: 10.34172/aim.2020.102

31. Alqahtani AM, AlMalki ZS, Alalweet RM, Almazrou SH, Alanazi AS, Alanazi $\mathrm{MA}$, et al. Assessing the severity of illness in patients with coronavirus disease in Saudi Arabia: a retrospective descriptive cross-sectional study. Front Public Health. (2020) 8:593256. doi: 10.3389/fpubh.2020.593256

32. Al-Sabah S, Al-Haddad M, Al-Youha S, Jamal M, Almazeedi S. COVID19: impact of obesity and diabetes on disease severity. Clin Obes. (2020) 10:e12414. doi: 10.1111/cob.12414

33. Alshukry A, Ali H, Ali Y, Al-Taweel T, Abu-Farha M, AbuBaker J, et al. Clinical characteristics of coronavirus disease 2019 (COVID-19) patients in Kuwait. PLoS ONE. (2020) 15:e0242768. doi: 10.1371/journal.pone.0242768

34. Argenziano MG, Bruce SL, Slater CL, Tiao JR, Baldwin MR, Barr RG, et al. Characterization and clinical course of 1000 patients with coronavirus disease 2019 in New York: retrospective case series. BMJ. (2020) 369:m1996. doi: 10.1136/bmj.m1996

35. Attaway AA, Zein J, Hatipoglu US. SARS-CoV-2 infection in the COPD population is associated with increased healthcare utilization: an analysis of Cleveland clinic's COVID-19 registry. EClinicalMedicine. (2020) 26:100515. doi: 10.1016/j.eclinm.2020.100515

36. Bahl A, Van Baalen MN, Ortiz L, Chen NW, Todd C, Milad M, et al. Early predictors of in-hospital mortality in patients with COVID-19 in a large American cohort. Intern. Emergency Med. (2020) 15:1485-99. doi: 10.1007/s11739-020-02509-7

37. Bartoletti M, Giannella M, Scudeller L, Tedeschi S, Rinaldi M, Bussini L, et al. Development and validation of a prediction model for severe respiratory failure in hospitalized patients with SARS-CoV-2 infection: a multicentre cohort study (PREDI-CO study). Clin Microbiol Infect. (2020) 26:1545-53. doi: 10.1016/j.cmi.2020.08.003

38. Bellan M, Patti G, Hayden E, Azzolina D, Pirisi M, Acquaviva A, et al. Fatality rate and predictors of mortality in an Italian cohort of hospitalized COVID19 patients. Sci Rep. (2020) 10:20731. doi: 10.1038/s41598-020-77698-4

39. Bepouka BI, Mandina M, Makulo JR, Longokolo M, Odio O, Mayasi N, et al. Predictors of mortality in COVID-19 patients at Kinshasa University Hospital, Democratic Republic of the Congo, from March to June 2020. Pan Afr Med J. (2020) 37:105. doi: 10.11604/pamj.2020.37.105.25279

40. Berenguer J, Ryan P, Rodríguez-Baño J, Jarrín I, Carratalà J, Pachón J, et al. Characteristics and predictors of death among 4035 consecutively hospitalized patients with COVID-19 in Spain. Clin Microbiol Infect. (2020) 26:1525-36. doi: 10.1016/j.cmi.2020.07.024

41. Bhargava A, Fukushima EA, Levine M, Zhao W, Tanveer F, Szpunar SM, et al. Predictors for severe COVID-19 infection. Clin Infect Dis. (2020) 71:1962-8. doi: $10.1093 / \mathrm{cid} / \mathrm{ciaa} 674$

42. Boari GEM, Chiarini G, Bonetti S, Malerba P, Bianco G, Faustini C, et al. Prognostic factors and predictors of outcome in patients with COVID-19 and related pneumonia: a retrospective cohort study. Biosci Rep. (2020) 40:BSR20203455. doi: 10.1042/bsr20203455

43. Borobia AM, Carcas AJ, Arnalich F, Álvarez-Sala R, Monserrat-Villatoro J, Quintana M, et al. A cohort of patients with COVID-19 in a major teaching hospital in Europe. J Clin Med. (2020) 9:1733. doi: 10.3390/jcm9061733

44. Brill SE, Jarvis HC, Ozcan E, Burns TLP, Warraich RA, Amani LJ, et al. COVID-19: a retrospective cohort study with focus on the over-80s and hospital-onset disease. BMC Med. (2020) 18:194. doi: 10.1186/s12916-020-01665-z

45. Buckner FS, McCulloch DJ, Atluri V, Blain M, McGuffin SA, Nalla AK, et al. Clinical features and outcomes of 105 hospitalized patients with COVID-19 in Seattle, Washington. Clin Infect Dis. (2020) 71:2167-73. doi: 10.1093/cid/ciaa632

46. Cai Q, Huang D, Ou P, Yu H, Zhu Z, Xia Z, et al. COVID-19 in a designated infectious diseases hospital outside Hubei Province, China. Allergy. (2020) 75:1742-52. doi: 10.1111/all.14309 
47. Caliskan T, Saylan B. Smoking and comorbidities are associated with COVID-19 severity and mortality in 565 patients treated in Turkey: a retrospective observational study. Rev Assoc Med Bras. (2020) 66:1679-84. doi: 10.1590/1806-9282.66.12.1679

48. Cao J, Tu WJ, Cheng W, Yu L, Liu YK, Hu X, et al. Clinical features and shortterm outcomes of 102 patients with coronavirus disease 2019 in Wuhan, China. Clin Infect Dis. (2020) 71:748-55. doi: 10.1093/cid/ciaa243

49. Cao Y, Han X, Gu J, Li Y, Liu J, Alwalid O, et al. Prognostic value of baseline clinical and HRCT findings in 101 patients with severe COVID19 in Wuhan, China. Sci Rep. (2020) 10:17543. doi: 10.1038/s41598-02074497-9

50. Carrillo-Vega MF, Salinas-Escudero G, García-Peña C, GutiérrezRobledo LM, Parra-Rodríguez L. Early estimation of the risk factors for hospitalization and mortality by COVID-19 in Mexico. PLoS ONE. (2020) 15:e0238905. doi: 10.1371/journal.pone.0238905

51. Cattelan AM, Di Meco E, Trevenzoli M, Frater A, Ferrari A, Villano M, et al. Clinical characteristics and laboratory biomarkers changes in COVID19 patients requiring or not intensive or sub-intensive care: a comparative study. BMC Infect Dis. (2020) 20:934. doi: 10.1186/s12879-020-05647-7

52. Cen Y, Chen X, Shen Y, Zhang XH, Lei Y, Xu C, et al. Risk factors for disease progression in patients with mild to moderate coronavirus disease 2019-a multi-centre observational study. Clin Microbiol Infect. (2020) 26:1242-7. doi: 10.1016/j.cmi.2020.05.041

53. Chen G, Wu D, Guo W, Cao Y, Huang D, Wang H, et al. Clinical and immunological features of severe and moderate coronavirus disease 2019. J Clin Invest. (2020) 130:2620-9. doi: 10.1172/jci137244

54. Chen Q, Zheng Z, Zhang C, Zhang X, Wu H, Wang J, et al. Clinical characteristics of 145 patients with corona virus disease 2019 (COVID-19) in Taizhou, Zhejiang, China. Infection. (2020) 48:543-51. doi: 10.1007/s15010-020-01432-5

55. Chen R, Liang W, Jiang M, Guan W, Zhan C, Wang T, et al. Risk factors of fatal outcome in hospitalized subjects with coronavirus disease 2019 from a nationwide analysis in China. Chest. (2020) 158:97-105. doi: 10.1016/j.chest.2020.04.010

56. Chen T, Dai Z, Mo P, Li X, Ma Z, Song S, et al. Clinical characteristics and outcomes of older patients with coronavirus disease 2019 (COVID-19) in Wuhan, China: a single-centered, retrospective study. J Gerontol A Biol Sci Med Sci. (2020) 75:1788-95. doi: 10.1093/gerona/glaa089

57. Chen T, Wu D, Chen H, Yan W, Yang D, Chen G, et al. Clinical characteristics of 113 deceased patients with coronavirus disease 2019: retrospective study. BMJ. (2020) 368:m1091. doi: 10.1136/bmj.m1091

58. Chinnadurai R, Ogedengbe O, Agarwal P, Money-Coomes S, Abdurrahman AZ, Mohammed S, et al. Older age and frailty are the chief predictors of mortality in COVID-19 patients admitted to an acute medical unit in a secondary care setting- a cohort study. BMC Geriatr. (2020) 20:409. doi: 10.1186/s12877-020-01803-5

59. Ciceri F, Castagna A, Rovere-Querini P, De Cobelli F, Ruggeri A, Galli L, et al. Early predictors of clinical outcomes of COVID-19 outbreak in Milan, Italy. Clin Immunol. (2020) 217:108509. doi: 10.1016/j.clim.2020.108509

60. Cocconcelli E, Biondini D, Giraudo C, Lococo S, Bernardinello N, Fichera G, et al. Clinical features and chest imaging as predictors of intensity of care in patients with COVID-19. J Clin Med. (2020) 9:2990. doi: $10.3390 /$ jcm 9092990

61. Colombi D, Bodini FC, Petrini M, Maffi G, Morelli N, Milanese G, et al. Wellaerated lung on admitting chest CT to predict adverse outcome in COVID-19 pneumonia. Radiology. (2020) 296:E86-96. doi: 10.1148/radiol.2020201433

62. Cortés-Tellés A, López-Romero S, Mancilla-Ceballos R, Ortíz-Farías DL, Núñez-Caamal N, Figueroa-Hurtado E. Risk factors for mortality in hospitalized patients with COVID-19: an overview in a mexican population. Tubercul Respir Dis. (2020) 83(Suppl. 1):S46-54. doi: 10.4046/trd.2020.0095

63. Covino M, De Matteis G, Santoro M, Sabia L, Simeoni B, Candelli M, et al. Clinical characteristics and prognostic factors in COVID-19 patients aged $\geq 80$ years. Geriatr Gerontol Int. (2020) 20:704-8. doi: 10.1111/ggi.13960

64. de Andrade CLT, Pereira CCA, Martins M, Lima SML, Portela MC. COVID19 hospitalizations in Brazil's Unified Health System (SUS). PLoS ONE. (2020) 15:e0243126. doi: 10.1371/journal.pone.0243126

65. de Souza CD, de Arruda Magalhães AJ, Lima AJ, Nunes DN, de Fátima Machado Soares É, de Castro Silva L, et al. Clinical manifestations and factors associated with mortality from COVID-19 in older adults: retrospective population-based study with 9807 older Brazilian COVID19 patients. Geriatr Gerontol Int. (2020) 20:1177-81. doi: 10.1111/ggi. 14061

66. Deng M, Qi Y, Deng L, Wang H, Xu Y, Li Z, et al. Obesity as a potential predictor of disease severity in young COVID-19 patients: a retrospective study. Obesity. (2020) 28:1815-25. doi: 10.1002/oby.22943

67. Deng Y, Liu W, Liu K, Fang YY, Shang J, Zhou L, et al. Clinical characteristics of fatal and recovered cases of coronavirus disease 2019 in Wuhan, China: a retrospective study. Chin Med J. (2020) 133:1261-7. doi: $10.1097 / \mathrm{cm} 9.0000000000000824$

68. Di Castelnuovo A, Bonaccio M, Costanzo S, Gialluisi A, Antinori A, Berselli $\mathrm{N}$, et al. Common cardiovascular risk factors and in-hospital mortality in 3,894 patients with COVID-19: survival analysis and machine learning-based findings from the multicentre Italian CORIST Study. Nutr Metab Cardiovasc Dis. (2020) 30:1899-913. doi: 10.1016/j.numecd.2020.07.031

69. Docherty AB, Harrison EM, Green CA, Hardwick HE, Pius R, Norman L, et al. Features of 20133 UK patients in hospital with covid-19 using the ISARIC WHO Clinical Characterisation Protocol: prospective observational cohort study. BMJ. (2020) 369:m1985. doi: 10.1136/bmj.m1985

70. Dreher M, Kersten A, Bickenbach J, Balfanz P, Hartmann B, Cornelissen C, et al. The characteristics of 50 hospitalized COVID-19 patients with and without ARDS. Deutsch Arzteblatt Int. (2020) 117:271-8. doi: 10.3238/arztebl.2020.0271

71. Du H, Pan X, Liu N, Chen J, Chen X, Werring DJ, et al. The effect of vascular risk factor burden on the severity of COVID-19 illness, a retrospective cohort study. Respir Res. (2020) 21:241. doi: 10.1186/s12931-020-01510-0

72. Du RH, Liang LR, Yang CQ, Wang W, Cao TZ, Li M, et al. Predictors of mortality for patients with COVID-19 pneumonia caused by SARSCoV- 2: a prospective cohort study. Eur Respir J. (2020) 55:2000524. doi: 10.1183/13993003.00524-2020

73. Du RH, Liu LM, Yin W, Wang W, Guan LL, Yuan ML, et al. Hospitalization and critical care of 109 decedents with COVID-19 Pneumonia in Wuhan, China. Ann Am Thorac Soc. (2020) 17:839-46. doi: 10.1513/AnnalsATS.202003-225OC

74. Duan J, Wang X, Chi J, Chen H, Bai L, Hu Q, et al. Correlation between the variables collected at admission and progression to severe cases during hospitalization among patients with COVID-19 in Chongqing. J Med Virol. (2020) 92:2616-22. doi: 10.1002/jmv.26082

75. Ebinger JE, Achamallah N, Ji H, Claggett BL, Sun N, Botting P, et al. Preexisting traits associated with Covid-19 illness severity. PLoS ONE. (2020) 15:e0236240. doi: 10.1371/journal.pone.0236240

76. Efrén M, Xóchitl T, Miguel H, Mónica R, Oliver M. Male gender and kidney illness are associated with an increased risk of severe laboratory-confirmed coronavirus disease. BMC Infect Dis. (2020) 20:674. doi: 10.1186/s12879-020-05408-6

77. Eliana F, Paolo GR, Stefania SA, Gianluca T, Gisella P, Olivia L, et al. Survival of hospitalized COVID-19 patients in Northern Italy: a populationbased cohort study by the ITA-COVID-19 network. Clin Epidemiol. (2020) 12:1337-46. doi: 10.2147/CLEP.S271763

78. El-Solh AA, Lawson Y, Carter M, El-Solh DA, Mergenhagen KA. Comparison of in-hospital mortality risk prediction models from COVID19. PLoS ONE. (2020) 15:e0244629. doi: 10.1371/journal.pone.0244629

79. Escalera-Antezana JP, Lizon-Ferrufino NF, Maldonado-Alanoca A, AlarconDe-la-Vega G, Alvarado-Arnez LE, Balderrama-Saavedra MA, et al. Risk factors for mortality in patients with Coronavirus Disease 2019 (COVID19) in Bolivia: an analysis of the first 107 confirmed cases. Le Infezioni Med. (2020) 28:238-42.

80. Feng Y, Ling Y, Bai T, Xie Y, Huang J, Li J, et al. COVID-19 with different severities: a multicenter study of clinical features. Am J Respir Crit Care Med. (2020) 201:1380-8. doi: 10.1164/rccm.202002-0445OC

81. Ferguson J, Rosser JI, Quintero O, Scott J, Subramanian A, Gumma $\mathrm{M}$, et al. Characteristics and outcomes of coronavirus disease patients under nonsurge conditions, Northern California, USA, March-April 2020. Emerg Infect Dis. (2020) 26:1679-85. doi: 10.3201/eid2608. 201776

82. Fumagalli C, Rozzini R, Vannini M, Coccia F, Cesaroni G, Mazzeo F, et al. Clinical risk score to predict in-hospital mortality in COVID-19 
patients: a retrospective cohort study. BMJ Open. (2020) 10:e040729. doi: 10.1136/bmjopen-2020-040729

83. Gao C, Cai Y, Zhang K, Zhou L, Zhang Y, Zhang X, et al. Association of hypertension and antihypertensive treatment with COVID-19 mortality: a retrospective observational study. Eur Heart J. (2020) 41:2058-66. doi: 10.1093/eurheartj/ehaa433

84. Gao J, Huang X, Gu H, Lou L, Xu Z. Predictive criteria of severe cases in COVID-19 patients of early stage: a retrospective observational study. J Clin Lab Anal. (2020) 34:e23562. doi: 10.1002/jcla.23562

85. Genet B, Vidal JS, Cohen A, Boully C, Beunardeau M, Marine Harlé L, et al. COVID-19 in-hospital mortality and use of renin-angiotensin system blockers in geriatrics patients. J Am Med Direct Assoc. (2020) 21:1539-45. doi: 10.1016/j.jamda.2020.09.004

86. Giacomelli A, Ridolfo AL, Milazzo L, Oreni L, Bernacchia D, Siano M, et al. 30-day mortality in patients hospitalized with COVID-19 during the first wave of the Italian epidemic: a prospective cohort study. Pharmacol Res. (2020) 158:104931. doi: 10.1016/j.phrs.2020.104931

87. Goodall JW, Reed TAN, Ardissino M, Bassett P, Whittington AM, Cohen DL, et al. Risk factors for severe disease in patients admitted with COVID-19 to a hospital in London, England: a retrospective cohort study. Epidemiol Infect. (2020) 148:e251. doi: 10.1017/s0950268820002472

88. Grasselli G, Greco M, Zanella A, Albano G, Antonelli M, Bellani G, et al. Risk factors associated with mortality among patients with COVID-19 in intensive care units in Lombardy, Italy. JAMA Intern Med. (2020) 180:134555. doi: 10.1001/jamainternmed.2020.3539

89. Gu T, Chu Q, Yu Z, Fa B, Li A, Xu L, et al. History of coronary heart disease increased the mortality rate of patients with COVID19: a nested case-control study. BMJ Open. (2020) 10:e038976. doi: 10.1136/bmjopen-2020-038976

90. Guan WJ, Ni ZY, Hu Y, Liang WH, Ou CQ, He JX, et al. Clinical characteristics of coronavirus disease 2019 in China. NEngl J Med. (2020) 382:1708-20. doi: 10.1056/NEJMoa2002032

91. Gupta N, Ish P, Kumar R, Dev N, Yadav SR, Malhotra N, et al. Evaluation of the clinical profile, laboratory parameters and outcome of two hundred COVID-19 patients from a tertiary centre in India. Monaldi Arch Chest Dis. (2020) 90:675-82. doi: 10.4081/monaldi.2020.1507

92. Gupta S, Hayek SS, Wang W, Chan L, Mathews KS, Melamed ML, et al. Factors associated with death in critically ill patients with coronavirus disease 2019 in the US. JAMA Intern Med. (2020) 180:1436-47. doi: 10.1001/jamainternmed.2020.3596

93. Hajifathalian K, Sharaiha RZ, Kumar S, Krisko T, Skaf D, Ang B, et al. Development and external validation of a prediction risk model for short-term mortality among hospitalized U.S. COVID-19 patients: a proposal for the COVID-AID risk tool. PLoS ONE. (2020) 15:e0239536. doi: 10.1371/journal.pone.0239536

94. Harrison SL, Fazio-Eynullayeva E, Lane DA, Underhill P, Lip GYH. Comorbidities associated with mortality in 31,461 adults with COVID-19 in the United States: a federated electronic medical record analysis. PLoS Med. (2020) 17:e1003321. doi: 10.1371/journal.pmed.1003321

95. He F, Ding XF, Cao M, Gong HY, Fu XZ, Luo J, et al. Comparative analysis of 95 patients with different severity in the early outbreak of COVID-19 in Wuhan, China. Can J Infect Dis Med Microbiol. (2020) 2020:4783062. doi: 10.1155/2020/4783062

96. He F, Luo Q, Lei M, Fan L, Shao X, Huang G, et al. Risk factors for severe cases of COVID-19: a retrospective cohort study. Aging. (2020) 12:15730-40. doi: 10.18632/aging.103803

97. He XW, Lai JS, Cheng J, Wang MW, Liu YJ, Xiao ZC, et al. Impact of complicated myocardial injury on the clinical outcome of severe or critically ill COVID-19 patients. Zhonghua Xin Xue Guan Bing Za Zhi. (2020) 48:45660. doi: 10.3760/cma.j.cn112148-20200228-00137

98. Hernández-Galdamez DR, González-Block M, Romo-Dueñas DK, LimaMorales R, Hernández-Vicente IA, Lumbreras-Guzmán M, et al. Increased risk of hospitalization and death in patients with COVID-19 and pre-existing noncommunicable diseases and modifiable risk factors in Mexico. Arch Med Res. (2020) 51:683-9. doi: 10.1016/j.arcmed.2020.07.003

99. Hong KS, Lee KH, Chung JH, Shin KC, Choi EY, Jin HJ, et al. Clinical features and outcomes of 98 patients hospitalized with SARS-CoV-2 infection in
Daegu, South Korea: a brief descriptive study. Yonsei Med J. (2020) 61:431-7. doi: 10.3349/ymj.2020.61.5.431

100. Hou H, Zhang B, Huang H, Luo Y, Wu S, Tang G, et al. Using IL$2 \mathrm{R} /$ lymphocytes for predicting the clinical progression of patients with COVID-19. Clin Exp Immunol. (2020) 201:76-84. doi: 10.1111/cei.13450

101. Hu L, Chen S, Fu Y, Gao Z, Long H, Ren HW, et al. Risk factors associated with clinical outcomes in 323 coronavirus disease 2019 (COVID19) hospitalized patients in Wuhan, China. Clin Infect Dis. (2020) 71:208998. doi: 10.1093/cid/ciaa539

102. Hu X, Hu C, Yang Y, Chen J, Zhong P, Wen Y, et al. Clinical characteristics and risk factors for severity of COVID-19 outside Wuhan: a doublecenter retrospective cohort study of 213 cases in Hunan, China. Ther Adv Respir Dis. (2020) 14:1753466620963035. doi: 10.1177/17534666209 63035

103. Huang C, Wang Y, Li X, Ren L, Zhao J, Hu Y, et al. Clinical features of patients infected with 2019 novel coronavirus in Wuhan, China. Lancet. (2020) 395:497-506. doi: 10.1016/s0140-6736(20)30183-5

104. Huang J, Cheng A, Kumar R, Fang Y, Chen G, Zhu Y, et al. Hypoalbuminemia predicts the outcome of COVID-19 independent of age and co-morbidity. $J$ Med Virol. (2020) 92:2152-8. doi: 10.1002/jmv.26003

105. Huang Q, Deng X, Li Y, Sun X, Chen Q, Xie M, et al. Clinical characteristics and drug therapies in patients with the common-type coronavirus disease 2019 in Hunan, China. Int J Clin Pharm. (2020) 42:83745. doi: 10.1007/s11096-020-01031-2

106. Huang R, Zhu L, Xue L, Liu L, Yan X, Wang J, et al. Clinical findings of patients with coronavirus disease 2019 in Jiangsu province, China: a retrospective, multi-center study. PLoS Negl Trop Dis. (2020) 14:e0008280. doi: 10.1371/journal.pntd.0008280

107. Huh K, Lee R, Ji W, Kang M, Hwang IC, Lee DH, et al. Impact of obesity, fasting plasma glucose level, blood pressure, and renal function on the severity of COVID-19: a matter of sexual dimorphism? Diabetes Res Clin Pract. (2020) 170:108515. doi: 10.1016/j.diabres.2020.108515

108. Hwang J, Ryu HS, Kim HA, Hyun M, Lee JY, Yi HA. Prognostic factors of COVID-19 infection in elderly patients: a multicenter study. J Clin Med. (2020) 9:3932. doi: 10.3390/jcm9123932

109. Hwang JM, Kim JH, Park JS, Chang MC, Park D. Neurological diseases as mortality predictive factors for patients with COVID19: a retrospective cohort study. Neurol Sci. (2020) 41:2317-24. doi: 10.1007/s10072-020-04541-z

110. Iaccarino G, Grassi G, Borghi C, Ferri C, Salvetti M, Volpe M. Age and multimorbidity predict death among COVID-19 patients: results of the SARS-RAS study of the Italian society of hypertension. Hypertension. (2020) 76:366-72. doi: 10.1161/hypertensionaha.120.15324

111. Ioannou GN, Locke E, Green P, Berry K, O’Hare AM, Shah JA, et al. Risk factors for hospitalization, mechanical ventilation, or death among 10131 US veterans with SARS-CoV-2 infection. JAMA Netw Open. (2020) 3:e2022310. doi: 10.1001/jamanetworkopen.2020.22310

112. Islam MZ, Riaz BK, Islam A, Khanam F, Akhter J, Choudhury R, et al. Risk factors associated with morbidity and mortality outcomes of COVID-19 patients on the 28th day of the disease course: a retrospective cohort study in Bangladesh. Epidemiol Infect. (2020) 148:e263. doi: $10.1017 / \mathrm{s} 0950268820002630$

113. Israelsen SB, Kristiansen KT, Hindsberger B, Ulrik CS, Andersen O, Jensen $\mathrm{M}$, et al. Characteristics of patients with COVID-19 pneumonia at Hvidovre Hospital, March-April 2020. Danish Med J. (2020) 67:A05200313.

114. Jiang Y, Abudurexiti S, An MM, Cao D, Wei J, Gong P. Risk factors associated with 28-day all-cause mortality in older severe COVID-19 patients in Wuhan, China: a retrospective observational study. Sci Rep. (2020) 10:22369. doi: 10.1038/s41598-020-79508-3

115. Jiménez E, Fontán-Vela M, Valencia J, Fernandez-Jimenez I, Álvaro-Alonso EA, Izquierdo-García E, et al. Characteristics, complications and outcomes among 1549 patients hospitalised with COVID-19 in a secondary hospital in Madrid, Spain: a retrospective case series study. BMJ Open. (2020) 10:e42398. doi: 10.1136/bmjopen-2020-042398

116. Jourdes A, Lafaurie M, Martin-Blondel G, Delobel P, Faruch M, Charpentier $\mathrm{S}$, et al. Clinical characteristics and outcome of hospitalized patients with SARS-CoV-2 infection at Toulouse University hospital (France). Results 
from the Covid-clinic-Toul cohort. La Revue Med Interne. (2020) 41:732-40. doi: 10.1016/j.revmed.2020.08.006

117. Kalligeros M, Shehadeh F, Mylona EK, Benitez G, Beckwith CG, Chan PA, et al. Association of obesity with disease severity among patients with coronavirus disease 2019. Obesity. (2020) 28:1200-4. doi: 10.1002/oby.22859

118. Karagiannidis C, Mostert C, Hentschker C, Voshaar T, Malzahn J, Schillinger G, et al. Case characteristics, resource use, and outcomes of 10021 patients with COVID-19 admitted to 920 German hospitals: an observational study. Lancet Respir Med. (2020) 8:853-62. doi: 10.1016/s2213-2600(20)30316-7

119. Kayina CA, Haritha D, Soni L, Behera S, Nair PR, Gouri M, et al. Epidemiological \& clinical characteristics \& early outcome of COVID-19 patients in a tertiary care teaching hospital in India: a preliminary analysis. Indian J Med Res. (2020) 152:100-4. doi: 10.4103/ijmr.IJMR_2890_20

120. Khamis F, Al-Zakwani I, Al Naamani H, Al Lawati S, Pandak N, Omar $\mathrm{MB}$, et al. Clinical characteristics and outcomes of the first 63 adult patients hospitalized with COVID-19: an experience from Oman. J Infect Public Health. (2020) 13:906-13. doi: 10.1016/j.jiph.2020.06.002

121. Kim SR, Nam SH, Kim YR. Risk factors on the progression to clinical outcomes of COVID-19 patients in South Korea: using national data. Int $J$ Environ Res Public Health. (2020) 17:8847. doi: 10.3390/ijerph17238847

122. Klang E, Kassim G, Soffer S, Freeman R, Levin MA, Reich DL. Severe obesity as an independent risk factor for COVID-19 mortality in hospitalized patients younger than 50. Obesity. (2020) 28:1595-9. doi: 10.1002/oby.22913

123. Kokoszka-Bargieł I, Cyprys P, Rutkowska K, Madowicz J, Knapik P. Intensive care unit admissions during the first 3 months of the COVID-19 pandemic in Poland: a single-center, cross-sectional study. Med Sci Monit. (2020) 26:e926974. doi: 10.12659/msm.926974

124. Kunal S, Sharma SM, Sharma SK, Gautam D, Bhatia H, Mahla H, et al. Cardiovascular complications and its impact on outcomes in COVID-19. Indian Heart J. (2020) 72:593-8. doi: 10.1016/j.ihj.2020.10.005

125. Labenz C, Kremer WM, Schattenberg JM, Wörns MA, Toenges G, Weinmann A, et al. Clinical Frailty Scale for risk stratification in patients with SARS-CoV-2 infection. J Invest Med. (2020) 68:1199-202. doi: 10.1136/jim-2020-001410

126. Lagi F, Piccica M, Graziani L, Vellere I, Botta A, Tilli M, et al. Early experience of an infectious and tropical diseases unit during the coronavirus disease (COVID-19) pandemic, Florence, Italy, February to March 2020. Euro Surveill. (2020) 25:2000556. doi: 10.2807/1560-7917.es.2020.25.17.2000556

127. Lee JY, Kim HA, Huh K, Hyun M, Rhee JY, Jang S, et al. Risk factors for mortality and respiratory support in elderly patients hospitalized with COVID-19 in Korea. J Korean Med Sci. (2020) 35:e223. doi: $10.3346 / \mathrm{jkms} .2020 .35 . \mathrm{e} 223$

128. Lei F, Liu YM, Zhou F, Qin JJ, Zhang P, Zhu L, et al. Longitudinal association between markers of liver injury and mortality in COVID-19 in China. Hepatology. (2020) 72:389-98. doi: 10.1002/hep.31301

129. Lei S, Jiang F, Su W, Chen C, Chen J, Mei W, et al. Clinical characteristics and outcomes of patients undergoing surgeries during the incubation period of COVID-19 infection. EClinicalMedicine. (2020) 21:100331. doi: $10.1016 /$ j.eclinm.2020.100331

130. Li G, Liu Y, Jing X, Wang Y, Miao M, Tao L, et al. Mortality risk of COVID19 in elderly males with comorbidities: a multi-country study. Aging. (2020) 13:27-60. doi: 10.18632/aging.202456

131. Li K, Wu J, Wu F, Guo D, Chen L, Fang Z, et al. The clinical and chest CT features associated with severe and critical COVID-19 pneumonia. Invest Radiol. (2020) 55:327-31. doi: 10.1097/rli.0000000000000672

132. Li T, Lu L, Zhang W, Tao Y, Wang L, Bao J, et al. Clinical characteristics of 312 hospitalized older patients with COVID-19 in Wuhan, China. Arch Gerontol Geriatr. (2020) 91:104185. doi: 10.1016/j.archger.2020. 104185

133. Li X, Xu S, Yu M, Wang K, Tao Y, Zhou Y, et al. Risk factors for severity and mortality in adult COVID-19 inpatients in Wuhan. J Allergy Clin Immunol. (2020) 146:110-8. doi: 10.1016/j.jaci.2020.04.006

134. Li Y, Liu T, Tse G, Wu M, Jiang J, Liu M, et al. Electrocardiograhic characteristics in patients with coronavirus infection: a single-center observational study. Ann Noninvasive Electrocardiol. (2020) 25:e12805. doi: $10.1111 /$ anec. 12805

135. Li YK, Peng S, Li LQ, Wang Q, Ping W, Zhang N, et al. Clinical and transmission characteristics of Covid-19 - a retrospective study of 25 cases from a single thoracic surgery department. Curr Med Sci. (2020) 40:295-300. doi: 10.1007/s11596-020-2176-2

136. Liang W, Liang H, Ou L, Chen B, Chen A, Li C, et al. Development and validation of a clinical risk score to predict the occurrence of critical illness in hospitalized patients with COVID-19. JAMA Intern Med. (2020) 180:1081-9. doi: 10.1001/jamainternmed.2020.2033

137. Liao Y, Feng Y, Wang B, Wang H, Huang J, Wu Y, et al. Clinical characteristics and prognostic factors of COVID-19 patients progression to severe: a retrospective, observational study. Aging. (2020) 12:18853-65. doi: 10.18632/aging.103931

138. Liu D, Cui P, Zeng S, Wang S, Feng X, Xu S, et al. Risk factors for developing into critical COVID-19 patients in Wuhan, China: a multicenter, retrospective, cohort study. EClinicalMedicine. (2020) 25:100471. doi: 10.1016/j.eclinm.2020.100471

139. Liu D, Wang Y, Wang J, Liu J, Yue Y, Liu W, et al. Characteristics and outcomes of a sample of patients with COVID-19 identified through social media in Wuhan, China: observational study. J Med Internet Res. (2020) 22:e20108. doi: 10.2196/20108

140. Liu F, Zhang Q, Huang C, Shi C, Wang L, Shi N, et al. CT quantification of pneumonia lesions in early days predicts progression to severe illness in a cohort of COVID-19 patients. Theranostics. (2020) 10:5613-22. doi: $10.7150 /$ thno. 45985

141. Liu J, Li S, Liu J, Liang B, Wang X, Wang H, et al. Longitudinal characteristics of lymphocyte responses and cytokine profiles in the peripheral blood of SARS-CoV-2 infected patients. EBioMedicine. (2020) 55:102763. doi: 10.1016/j.ebiom.2020.102763

142. Liu M, Han S, Liao Q, Chang L, Tan Y, Jia P, et al. Outcomes and prognostic factors in 70 non-survivors and 595 survivors with COVID-19 in Wuhan, China. Transbound Emerg Dis. (2020). doi: 10.1111/tbed.13969

143. Liu S, Luo H, Wang Y, Cuevas LE, Wang D, Ju S, et al. Clinical characteristics and risk factors of patients with severe COVID-19 in Jiangsu province, China: a retrospective multicentre cohort study. BMC Infect Dis. (2020) 20:584. doi: 10.1186/s12879-020-05314-x

144. Liu SP, Zhang Q, Wang W, Zhang M, Liu C, Xiao X, et al. Hyperglycemia is a strong predictor of poor prognosis in COVID-19. Diabetes Res Clin Pract. (2020) 167:108338. doi: 10.1016/j.diabres.2020.108338

145. Lodigiani C, Iapichino G, Carenzo L, Cecconi M, Ferrazzi P, Sebastian T, et al. Venous and arterial thromboembolic complications in COVID-19 patients admitted to an academic hospital in Milan, Italy. Thrombosis Res. (2020) 191:9-14. doi: 10.1016/j.thromres.2020.04.024

146. Lu Y, Sun K, Guo S, Wang J, Li A, Rong X, et al. Early warning indicators of severe COVID-19: a single-center study of cases from Shanghai, China. Front Med. (2020) 7:432. doi: 10.3389/fmed.2020.00432

147. Luo X, Zhou W, Yan X, Guo T, Wang B, Xia H, et al. Prognostic value of C-reactive protein in patients with coronavirus 2019. Clin Infect Dis. (2020) 71:2174-9. doi: $10.1093 /$ cid/ciaa641

148. Zamanian M, Foroozanfar Z, Izadi Z, Jafari S, Derakhshankhah H, Salimi M. Association of underlying diseases and clinical characteristics with mortality in patients with 2019 novel coronavirus in Iran. Arch Clin Infect Dis. (2020) 15:1-9. doi: 10.5812/archcid.104621

149. Ma X, Li A, Jiao M, Shi Q, An X, Feng Y, et al. Characteristic of 523 COVID19 in Henan Province and a death prediction model. Front Public Health. (2020) 8:475. doi: 10.3389/fpubh.2020.00475

150. Macedo MCF, Pinheiro IM, Carvalho CJL, Fraga H, Araujo IPC, Montes SS, et al. Correlation between hospitalized patients' demographics, symptoms, comorbidities, and COVID-19 pandemic in Bahia, Brazil. PLoS ONE. (2020) 15:e0243966. doi: 10.1371/journal.pone.0243966

151. Mao L, Jin H, Wang M, Hu Y, Chen S, He Q, et al. Neurologic manifestations of hospitalized patients with coronavirus disease 2019 in Wuhan, China. JAMA Neurol. (2020) 77:683-90. doi: 10.1001/jamaneurol.2020.1127

152. Mendes A, Serratrice C, Herrmann FR, Genton L, Périvier S, Scheffler M, et al. Predictors of in-hospital mortality in older patients with COVID19: the COVIDAge study. J Am Med Direct Assoc. (2020) 21:1546-54. doi: 10.1016/j.jamda.2020.09.014

153. Monteiro AC, Suri R, Emeruwa IO, Stretch RJ, Cortes-Lopez RY, Sherman A, et al. Obesity and smoking as risk factors for invasive mechanical ventilation in COVID-19: a retrospective, observational cohort study. PLoS ONE. (2020) 15:e0238552. doi: 10.1371/journal.pone.0238552 
154. Nachega JB, Ishoso DK, Otokoye JO, Hermans MP, Machekano RN, Sam-Agudu NA, et al. Clinical characteristics and outcomes of patients hospitalized for COVID-19 in Africa: early insights from the democratic republic of the Congo. Am J Trop Med Hyg. (2020) 103:2419-28. doi: 10.4269/ajtmh.20-1240

155. Nikpouraghdam M, Jalali Farahani A, Alishiri G, Heydari S, Ebrahimnia M, Samadinia H, et al. Epidemiological characteristics of coronavirus disease 2019 (COVID-19) patients in IRAN: a single center study. J Clin Virol. (2020) 127:104378. doi: 10.1016/j.jcv.2020.104378

156. Okoh AK, Sossou C, Dangayach NS, Meledathu S, Phillips O, Raczek C, et al. Coronavirus disease 19 in minority populations of Newark, New Jersey. Int J Equity Health. (2020) 19:93. doi: 10.1186/s12939-020-01208-1

157. Omrani AS, Almaslamani MA, Daghfal J, Alattar RA, Elgara M, Shaar SH, et al. The first consecutive 5000 patients with Coronavirus Disease 2019 from Qatar; a nation-wide cohort study. BMC Infect Dis. (2020) 20:777. doi: 10.1186/s12879-020-05511-8

158. Ortiz-Brizuela E, Villanueva-Reza M, González-Lara MF, Tamez-Torres KM, Román-Montes CM, Díaz-Mejía BA, et al. Clinical and epidemiological characteristics of patients diagnosed with COVID-19 in a tertiary care center in Mexico city: a prospective cohort study. Rev Invest Clin. (2020) 72:252-8. doi: 10.24875/ric.20000334

159. Pan F, Yang L, Li Y, Liang B, Li L, Ye T, et al. Factors associated with death outcome in patients with severe coronavirus disease-19 (COVID-19): a case-control study. Int J Med Sci. (2020) 17:1281-92. doi: 10.7150/ijms.46614

160. Peng XP, Hua TR, Song L, Yue ZZ, Bin F, Ming WX, et al. Risk factors for adverse clinical outcomes with COVID-19 in China: a multicenter, retrospective, observational study. Theranostics. (2020) 10:6372-83. doi: $10.7150 /$ thno.46833

161. Petrilli CM, Jones SA, Yang J, Rajagopalan H, O’Donnell L, Chernyak Y, et al. Factors associated with hospital admission and critical illness among 5279 people with coronavirus disease 2019 in New York City: prospective cohort study. BMJ. (2020) 369:m1966. doi: 10.1136/bmj.m1966

162. Polverino F, Stern DA, Ruocco G, Balestro E, Bassetti M, Candelli M, et al. Comorbidities, cardiovascular therapies, and COVID-19 mortality: a nationwide, Italian Observational Study (ItaliCO). Front Cardiovasc Med. (2020) 7:585866. doi: 10.3389/fcvm.2020.585866

163. Popov GT, Baymakova M, Vaseva V, Kundurzhiev T, Mutafchiyski V. Clinical characteristics of hospitalized patients with COVID-19 in Sofia, Bulgaria. Vector Borne Zoonot Dis. (2020) 20:910-5. doi: 10.1089/vbz.2020.2679

164. Rastad H, Karim H, Ejtahed HS, Tajbakhsh R, Noorisepehr M, Babaei M, et al. Risk and predictors of in-hospital mortality from COVID-19 in patients with diabetes and cardiovascular disease. Diabetol Metab Syndr. (2020) 12:57. doi: 10.1186/s13098-020-00565-9

165. Rath D, Petersen-Uribe Á, Avdiu A, Witzel K, Jaeger P, Zdanyte M, et al. Impaired cardiac function is associated with mortality in patients with acute COVID-19 infection. Clin Res Cardiol. (2020) 109:1491-9. doi: 10.1007/s00392-020-01683-0

166. Ren H, Yang Y, Wang F, Yan Y, Shi X, Dong K, et al. Association of the insulin resistance marker TyG index with the severity and mortality of COVID-19. Cardiovasc Diabetol. (2020) 19:58. doi: 10.1186/s12933-020-01035-2

167. Renieris G, Katrini K, Damoulari C, Akinosoglou K, Psarrakis C, Kyriakopoulou M, et al. Serum hydrogen sulfide and outcome association in pneumonia by the SARS-CoV-2 coronavirus. Shock. (2020) 54:633-7. doi: $10.1097 /$ shk.0000000000001562

168. Rivera-Izquierdo M, Del Carmen Valero-Ubierna M, JL Rd, FernándezGarcía M, Martínez-Diz S, Tahery-Mahmoud A, et al. Sociodemographic, clinical and laboratory factors on admission associated with COVID-19 mortality in hospitalized patients: a retrospective observational study. PLoS ONE. (2020) 15:e0235107. doi: 10.1371/journal.pone.0235107

169. Rodilla E, Saura A, Jiménez I, Mendizábal A, Pineda-Cantero A, LorenzoHernández E, et al. Association of hypertension with all-cause mortality among hospitalized patients with COVID-19. J Clin Med. (2020) 9:3136. doi: $10.3390 / \mathrm{jcm} 9103136$

170. Rokni M, Ahmadikia K, Asghari S, Mashaei S, Hassanali F. Comparison of clinical, para-clinical and laboratory findings in survived and deceased patients with COVID-19: diagnostic role of inflammatory indications in determining the severity of illness. BMC Infect Dis. (2020) 20:869. doi: 10.1186/s12879-020-05540-3
171. Romero-Sánchez CM, Díaz-Maroto I, Fernández-Díaz E, SánchezLarsen Á, Layos-Romero A, García-García J, et al. Neurologic manifestations in hospitalized patients with COVID-19: The ALBACOVID registry. Neurology. (2020) 95:e1060-70. doi: 10.1212/wnl.00000000000 09937

172. Rosenthal N, Cao Z, Gundrum J, Sianis J, Safo S. Risk factors associated with in-hospital mortality in a US national sample of patients with COVID-19. JAMA Netw Open. (2020) 3:e2029058. doi: 10.1001/jamanetworkopen.2020.29058

173. Russo V, Di Maio M, Attena E, Silverio A, Scudiero F, Celentani D, et al. Clinical impact of pre-admission antithrombotic therapy in hospitalized patients with COVID-19: a multicenter observational study. Pharmacol Res. (2020) 159:104965. doi: 10.1016/j.phrs.2020.104965

174. Lapthorne S, Faller E, Barry R, O'sullivan M, Finnegan P, Everard C, et al. Clinical characteristics and factors associated with severity in patients admitted with SARS-CoV-2 infection. Irish Med J. (2020) 113:1-11.

175. Saleh A, Matsumori A, Abdelrazek S, Eltaweel S, Salous A, Neumann FJ, et al. Myocardial involvement in coronavirus disease 19. Herz. (2020) 45:719-25. doi: 10.1007/s00059-020-05001-2

176. Salvatore P, Andrea D, Elia V, Devis B, Massimo M, G GC, et al. Abnormal liver function tests predict transfer to intensive care unit and death in COVID-19. Liver Int. (2020) 40:2394-406. doi: 10.1111/liv.14565

177. Sanchez-Pina JM, Rodríguez Rodriguez M, Castro Quismondo N, Gil Manso R, Colmenares R, Gil Alos D, et al. Clinical course and risk factors for mortality from COVID-19 in patients with haematological malignancies. Eur J Haematol. (2020) 105:597-607. doi: 10.1111/ejh.13493

178. Shah C, Grando DJ, Rainess RA, Ayad L, Gobran E, Benson P, et al. Factors associated with increased mortality in hospitalized COVID-19 patients. Ann Med Surg. (2020) 60:308-13. doi: 10.1016/j.amsu.2020.10.071

179. Shang W, Dong J, Ren Y, Tian M, Li W, Hu J, et al. The value of clinical parameters in predicting the severity of COVID-19. J Med Virol. (2020) 92:2188-92. doi: 10.1002/jmv.26031

180. Simonnet A, Chetboun M, Poissy J, Raverdy V, Noulette J, Duhamel A, et al. High prevalence of obesity in severe acute respiratory syndrome coronavirus-2 (SARS-CoV-2) requiring invasive mechanical ventilation. Obesity. (2020) 28:1195-9. doi: 10.1002/oby.22831

181. Smadja DM, Guerin CL, Chocron R, Yatim N, Boussier J, Gendron N, et al. Angiopoietin-2 as a marker of endothelial activation is a good predictor factor for intensive care unit admission of COVID-19 patients. Angiogenesis. (2020) 23:611-20. doi: 10.1007/s10456-020-09730-0

182. Smith AA, Fridling J, Ibrahim D, Porter PS Jr. Identifying patients at greatest risk of mortality due to COVID-19: a new england perspective. Western J Emergency Med. (2020) 21:785-9. doi: 10.5811/westjem.2020.6.47957

183. Sun L, Shen L, Fan J, Gu F, Hu M, An Y, et al. Clinical features of patients with coronavirus disease 2019 from a designated hospital in Beijing, China. $J$ Med Virol. (2020) 92:2055-66. doi: 10.1002/jmv.25966

184. Tambe MP, Parande MA, Tapare VS, Borle PS, Lakde RN, Shelke SC. An epidemiological study of laboratory confirmed COVID-19 cases admitted in a tertiary care hospital of Pune, Maharashtra. Indian J Public Health. (2020) 64(Suppl.):S183-7. doi: 10.4103/ijph.IJPH_522_20

185. Trecarichi EM, Mazzitelli M, Serapide F, Pelle MC, Tassone B, Arrighi E, et al. Clinical characteristics and predictors of mortality associated with COVID19 in elderly patients from a long-term care facility. Sci Rep. (2020) 10:20834. doi: 10.1038/s41598-020-77641-7

186. Vrillon A, Hourregue C, Azuar J, Grosset L, Boutelier A, Tan S, et al. COVID19 in older adults: a series of 76 patients aged 85 years and older with COVID-19. J Am Geriatr Soc. (2020) 68:2735-43. doi: 10.1111/jgs.16894

187. Wan S, Xiang Y, Fang W, Zheng Y, Li B, Hu Y, et al. Clinical features and treatment of COVID-19 patients in northeast Chongqing. J Med Virol. (2020) 92:797-806. doi: 10.1002/jmv.25783

188. Wang A, Gao G, Wang S, Chen M, Qian F, Tang W, et al. Clinical characteristics and risk factors of acute respiratory distress syndrome (ARDS) in COVID-19 patients in Beijing, China: a retrospective study. Med Sci Monit. (2020) 26:e925974. doi: 10.12659/msm.925974

189. Wang D, Hu B, Hu C, Zhu F, Liu X, Zhang J, et al. Clinical characteristics of 138 hospitalized patients with 2019 novel coronavirus-infected pneumonia in Wuhan, China. JAMA. (2020) 323:1061-9.. doi: 10.1001/jama.2020. 1585 
190. Wang D, Yin Y, Hu C, Liu X, Zhang X, Zhou S, et al. Clinical course and outcome of 107 patients infected with the novel coronavirus, SARS-CoV-2, discharged from two hospitals in Wuhan, China. Crit Care. (2020) 24:188. doi: 10.1186/s13054-020-02895-6

191. Wang F, Yang Y, Dong K, Yan Y, Zhang S, Ren H, et al. Clinical characteristics of 28 patients with diabetes and COVID-19 in Wuhan, China. Endocr Pract. (2020) 26:668-74. doi: 10.4158/ep-2020-0108

192. Wang J, Guo S, Zhang Y, Gao K, Zuo J, Tan N, et al. Clinical features and risk factors for severe inpatients with COVID-19: a retrospective study in China. PLoS ONE. (2020) 15:e0244125. doi: 10.1371/journal.pone.0244125

193. Wang L, He W, Yu X, Hu D, Bao M, Liu H, et al. Coronavirus disease 2019 in elderly patients: characteristics and prognostic factors based on 4-week follow-up. J Infect. (2020) 80:639-45. doi: 10.1016/j.jinf.2020.03.019

194. Wang Q, Zhao H, Liu LG, Wang YB, Zhang T, Li MH, et al. Pattern of liver injury in adult patients with COVID-19: a retrospective analysis of 105 patients. Milit Med Res. (2020) 7:28. doi: 10.1186/s40779-020-00256-6

195. Wang Y, Lu X, Li Y, Chen H, Chen T, Su N, et al. Clinical course and outcomes of 344 intensive care patients with COVID-19. Am J Respir Crit Care Med. (2020) 201:1430-4. doi: 10.1164/rccm.202003-0736LE

196. Wei X, Su J, Yang K, Wei J, Wan H, Cao X, et al. Elevations of serum cancer biomarkers correlate with severity of COVID-19. J Med Virol. (2020) 92:2036-41. doi: 10.1002/jmv.25957

197. Wei Y, Zeng W, Huang X, Li J, Qiu X, Li H, et al. Clinical characteristics of 276 hospitalized patients with coronavirus disease 2019 in Zengdu District, Hubei Province: a single-center descriptive study. BMC Infect Dis. (2020) 20:549. doi: 10.1186/s12879-020-05252-8

198. Wendel Garcia PD, Fumeaux T, Guerci P, Heuberger DM, Montomoli J, Roche-Campo F, et al. Prognostic factors associated with mortality risk and disease progression in 639 critically ill patients with COVID19 in Europe: initial report of the international RISC-19-ICU prospective observational cohort. EClinicalMedicine. (2020) 25:100449. doi: 10.1016/j.eclinm.2020.100449

199. Wu C, Chen X, Cai Y, Xia J, Zhou X, Xu S, et al. Risk factors associated with acute respiratory distress syndrome and death in patients with coronavirus disease 2019 pneumonia in Wuhan, China. JAMA Intern Med. (2020) 180:934-43. doi: 10.1001/jamainternmed.2020.0994

200. Wu J, Li W, Shi X, Chen Z, Jiang B, Liu J, et al. Early antiviral treatment contributes to alleviate the severity and improve the prognosis of patients with novel coronavirus disease (COVID-19). J Intern Med. (2020) 288:12838. doi: 10.1111/joim.13063

201. Xia X, Wen M, Zhan S, He J, Chen W. An increased neutrophil/lymphocyte ratio is an early warning signal of severe COVID-19. Nan Fang Yi Ke Da Xue Xue Bao. (2020) 40:333-6. doi: 10.12122/j.issn.1673-4254.2020.03.06

202. Xiao LS, Zhang WF, Gong MC, Zhang YP, Chen LY, Zhu HB, et al. Development and validation of the HNC-LL score for predicting the severity of coronavirus disease 2019. EBioMedicine. (2020) 57:102880. doi: 10.1016/j.ebiom.2020.102880

203. Xie H, Zhao J, Lian N, Lin S, Xie Q, Zhuo H. Clinical characteristics of nonICU hospitalized patients with coronavirus disease 2019 and liver injury: a retrospective study. Liver Int. (2020) 40:1321-6. doi: 10.1111/liv.14449

204. Xie J, Wu W, Li S, Hu Y, Hu M, Li J, et al. Clinical characteristics and outcomes of critically ill patients with novel coronavirus infectious disease (COVID-19) in China: a retrospective multicenter study. Intensive Care Med. (2020) 46:1863-72. doi: 10.1007/s00134-020-06211-2

205. Xie Y, You Q, Wu C, Cao S, Qu G, Yan X, et al. Impact of cardiovascular disease on clinical characteristics and outcomes of coronavirus disease 2019 (COVID-19). Circ J. (2020) 84:1277-83. doi: 10.1253/circj.CJ-20-0348

206. Xiong S, Lin L, Feng L, Jinhu S, Lei H, Huijian L, et al. Clinical characteristics of 116 hospitalized patients with COVID-19 in Wuhan, China: a singlecentered, retrospective, observational study. BMC Infect Dis. (2020) 20:787. doi: 10.1186/s12879-020-05452-2

207. Xu J, Yang X, Yang L, Zou X, Wang Y, Wu Y, et al. Clinical course and predictors of 60-day mortality in 239 critically ill patients with COVID19: a multicenter retrospective study from Wuhan, China. Crit Care. (2020) 24:394. doi: 10.1186/s13054-020-03098-9

208. Yan X, Han X, Peng D, Fan Y, Fang Z, Long D, et al. Clinical characteristics and prognosis of 218 patients with COVID-19: a retrospective study based on clinical classification. Front Med. (2020) 7:485. doi: 10.3389/fmed.2020.00485
209. Yan Y, Yang Y, Wang F, Ren H, Zhang S, Shi X, et al. Clinical characteristics and outcomes of patients with severe covid-19 with diabetes. BMJ Open Diabetes Res Care. (2020) 8:e001343. doi: 10.1136/bmjdrc-2020-001343

210. Yang Q, Xie L, Zhang W, Zhao L, Wu H, Jiang J, et al. Analysis of the clinical characteristics, drug treatments and prognoses of 136 patients with coronavirus disease 2019. J Clin Pharm Ther. (2020) 45:609-16. doi: $10.1111 /$ jcpt.13170

211. Yang Q, Zhou Y, Wang X, Gao S, Xiao Y, Zhang W, et al. Effect of hypertension on outcomes of adult inpatients with COVID-19 in Wuhan, China: a propensity score-matching analysis. Respir Res. (2020) 21:172. doi: 10.1186/s12931-020-01435-8

212. Yang X, Yu Y, Xu J, Shu H, Xia J, Liu H, et al. Clinical course and outcomes of critically ill patients with SARS-CoV-2 pneumonia in Wuhan, China: a single-centered, retrospective, observational study. Lancet Respir Med. (2020) 8:475-81. doi: 10.1016/s2213-2600(20)30079-5

213. Yao Q, Wang P, Wang X, Qie G, Meng M, Tong X, et al. A retrospective study of risk factors for severe acute respiratory syndrome coronavirus 2 infections in hospitalized adult patients. Pol Arch Intern Med. (2020) 130:390-9. doi: 10.20452/pamw.15312

214. Ye C, Zhang S, Zhang X, Cai H, Gu J, Lian J, et al. Impact of comorbidities on patients with COVID-19: a large retrospective study in Zhejiang, China. J Med Virol. (2020) 92:2821-9. doi: 10.1002/jmv.26183

215. Yi P, Yang X, Ding C, Chen Y, Xu K, Ni Q, et al. Risk factors and clinical features of deterioration in COVID-19 patients in Zhejiang, China: a single-centre, retrospective study. BMC Infect Dis. (2020) 20:943. doi: 10.1186/s12879-020-05682-4

216. Yu C, Lei Q, Li W, Wang X, Liu W, Fan X, et al. Clinical characteristics, associated factors, and predicting COVID-19 mortality risk: a retrospective study in Wuhan, China. Am J Prev Med. (2020) 59:168-75. doi: 10.1016/j.amepre.2020.05.002

217. Yuan M, Yin W, Tao Z, Tan W, Hu Y. Association of radiologic findings with mortality of patients infected with 2019 novel coronavirus in Wuhan, China. PLoS ONE. (2020) 15:e0230548. doi: 10.1371/journal.pone.0230548

218. Yun K, Lee JS, Kim EY, Chandra H, Oh BL, Oh J. Severe COVID-19 illness: risk factors and its burden on critical care resources. Front Med. (2020) 7:583060. doi: 10.3389/fmed.2020.583060

219. Zeng JH, Wu WB, Qu JX, Wang Y, Dong CF, Luo YF, et al. Cardiac manifestations of COVID-19 in Shenzhen, China. Infection. (2020) 48:86170. doi: 10.1007/s15010-020-01473-w

220. Zhang G, Zhang J, Wang B, Zhu X, Wang Q, Qiu S. Analysis of clinical characteristics and laboratory findings of 95 cases of 2019 novel coronavirus pneumonia in Wuhan, China: a retrospective analysis. Respir Res. (2020) 21:74. doi: 10.1186/s12931-020-01338-8

221. Zhang J, Wang $\mathrm{X}$, Jia $\mathrm{X}, \mathrm{Li} \mathrm{J}, \mathrm{Hu} \mathrm{K}$, Chen $\mathrm{G}$, et al. Risk factors for disease severity, unimprovement, and mortality in COVID-19 patients in Wuhan, China. Clin Microbiol Infect. (2020) 26:767-72. doi: 10.1016/j.cmi.2020.04.012

222. Zhang J, Yu M, Tong S, Liu LY, Tang LV. Predictive factors for disease progression in hospitalized patients with coronavirus disease 2019 in Wuhan, China. J Clin Virol. (2020) 127:104392. doi: 10.1016/j.jcv.2020.104392

223. Zhang JJ, Dong X, Cao YY, Yuan YD, Yang YB, Yan YQ, et al. Clinical characteristics of 140 patients infected with SARS-CoV-2 in Wuhan, China. Allergy. (2020) 75:1730-41. doi: 10.1111/all.14238

224. Zhang N, Xu X, Zhou LY, Chen G, Li Y, Yin H, et al. Clinical characteristics and chest CT imaging features of critically ill COVID-19 patients. Eur Radiol. (2020) 30:6151-60. doi: 10.1007/s00330-020-06955-x

225. Zhang R, Ouyang H, Fu L, Wang S, Han J, Huang K, et al. CT features of SARS-CoV-2 pneumonia according to clinical presentation: a retrospective analysis of 120 consecutive patients from Wuhan city. Eur Radiol. (2020) 30:4417-26. doi: 10.1007/s00330-020-06854-1

226. Zhang S, Liu L, Yang B, Li R, Luo J, Huang J, et al. Clinical characteristics of 134 convalescent patients with COVID-19 in Guizhou, China. Respir Res. (2020) 21:314. doi: 10.1186/s12931-020-01580-0

227. Zhang SX, Li J, Zhou P, Na JR, Liu BF, Zheng XW, et al. The analysis of clinical characteristics of 34 novel coronavirus pneumonia cases in Ningxia Hui autonomous region. Zhonghua Jie He He Hu Xi Za Zhi. (2020) 43:431-6. doi: 10.3760/cma.j.cn112147-20200219-00121 
228. Zhang SY, Lian JS, Hu JH, Zhang XL, Lu YF, Cai H, et al. Clinical characteristics of different subtypes and risk factors for the severity of illness in patients with COVID-19 in Zhejiang, China. Infect Dis Poverty. (2020) 9:85. doi: 10.1186/s40249-020-00710-6

229. Zhang Y, Cui Y, Shen M, Zhang J, Liu B, Dai M, et al. Association of diabetes mellitus with disease severity and prognosis in COVID-19: a retrospective cohort study. Diabetes Res Clin Pract. (2020) 165:108227. doi: 10.1016/j.diabres.2020.108227

230. Zhang YT, Deng AP, Hu T, Chen XG, Zhuang YL, Tan XH, et al. [Clinical outcomes of COVID-19 cases and influencing factors in Guangdong province]. Zhonghua liu xing bing xue za zhi. (2020) 41:1999-2004. doi: 10.3760/cma.j.cn112338-20200318-00378

231. Zhao S, Lin Y, Zhou C, Wang L, Chen X, Clifford SP, et al. Shortterm outcomes of patients with COVID-19 undergoing invasive mechanical ventilation: a retrospective observational study from Wuhan, China. Front Med. (2020) 7:571542. doi: 10.3389/fmed.2020. 571542

232. Zhao X, Wang K, Zuo P, Liu Y, Zhang M, Xie S, et al. Early decrease in blood platelet count is associated with poor prognosis in COVID-19 patientsindications for predictive, preventive, and personalized medical approach. Epma J. (2020) 11:1-7. doi: 10.1007/s13167-020-00208-Z

233. Zhao XY, Xu XX, Yin HS, Hu QM, Xiong T, Tang YY, et al. Clinical characteristics of patients with 2019 coronavirus disease in a non-Wuhan area of Hubei Province, China: a retrospective study. BMC Infect Dis. (2020) 20:311. doi: 10.1186/s12879-020-05010-w

234. Zhao Y, Nie HX, Hu K, Wu XJ, Zhang YT, Wang MM, et al. Abnormal immunity of non-survivors with COVID-19: predictors for mortality. Infect Dis Poverty. (2020) 9:108. doi: 10.1186/s40249-020-00723-1

235. Zheng F, Tang W, Li H, Huang YX, Xie YL, Zhou ZG. Clinical characteristics of 161 cases of corona virus disease 2019 (COVID-19) in Changsha. Eur Rev Med Pharmacol Sci. (2020) 24:3404-10. doi: 10.26355/eurrev_202003_20711

236. Zheng Y, Xiong C, Liu Y, Qian X, Tang Y, Liu L, et al. Epidemiological and clinical characteristics analysis of COVID-19 in the surrounding areas of Wuhan, Hubei Province in 2020. Pharmacol Res. (2020) 157:104821. doi: 10.1016/j.phrs.2020.104821

237. Zheng $\mathrm{Y}, \mathrm{Xu} \mathrm{H}$, Yang $\mathrm{M}$, Zeng $\mathrm{Y}$, Chen $\mathrm{H}$, Liu R, et al. Epidemiological characteristics and clinical features of 32 critical and 67 noncritical cases of COVID-19 in Chengdu. J Clin Virol. (2020) 127:104366. doi: 10.1016/j.jcv.2020.104366

238. Zhou F, Yu T, Du R, Fan G, Liu Y, Liu Z, et al. Clinical course and risk factors for mortality of adult inpatients with COVID-19 in Wuhan, China: a retrospective cohort study. Lancet. (2020) 395:1054-62. doi: 10.1016/s0140-6736(20)30566-3

239. Zhou W, Ye S, Wang W, Li S, Hu Q. Clinical features of COVID-19 patients with diabetes and secondary hyperglycemia. J Diabetes Res. (2020) 2020:3918723. doi: 10.1155/2020/3918723

240. Zhou Y, He Y, Yang H, Yu H, Wang T, Chen Z, et al. Development and validation a nomogram for predicting the risk of severe COVID-19: a multi-center study in Sichuan, China. PLoS ONE. (2020) 15:e0233328. doi: 10.1371/journal.pone.0233328

241. Zhu Z, Cai T, Fan L, Lou K, Hua X, Huang Z, et al. Clinical value of immuneinflammatory parameters to assess the severity of coronavirus disease 2019. Int J Infect Dis. (2020) 95:332-9. doi: 10.1016/j.ijid.2020.04.041

242. Zou L, Dai L, Zhang Y, Fu W, Gao Y, Zhang Z, et al. Clinical characteristics and risk factors for disease severity and death in patients with coronavirus disease 2019 in Wuhan, China. Front Med. (2020) 7:532. doi: 10.3389/fmed.2020.00532
243. Zou X, Li S, Fang M, Hu M, Bian Y, Ling J, et al. Acute physiology and chronic health evaluation II score as a predictor of hospital mortality in patients of coronavirus disease 2019. Crit Care Med. (2020) 48:e657-65. doi: $10.1097 / \mathrm{ccm} .0000000000004411$

244. Rodriguez-Morales AJ, Cardona-Ospina JA, Gutiérrez-Ocampo E, Villamizar-Peña R, Holguin-Rivera Y, Escalera-Antezana JP, et al. Clinical, laboratory and imaging features of COVID-19: a systematic review and meta-analysis. Travel Med Infect Dis. (2020) 34:101623. doi: 10.1016/j.tmaid.2020.101623

245. Wang B, Li R, Lu Z, Huang Y. Does comorbidity increase the risk of patients with COVID-19: evidence from meta-analysis. Aging. (2020) 12:6049-57. doi: 10.18632/aging.103000

246. Mattiuzzi C, Lippi G. Worldwide asthma epidemiology: insights from the Global Health Data Exchange database. Int Forum Allergy Rhinol. (2020) 10:75-80. doi: 10.1002/alr.22464

247. Chhiba KD, Patel GB, Vu THT, Chen MM, Guo A, Kudlaty E, et al. Prevalence and characterization of asthma in hospitalized and nonhospitalized patients with COVID-19. J Allergy Clin Immunol. (2020) 146:307-14.e4. doi: 10.1016/j.jaci.2020.06.010

248. Wu T, Yu P, Li Y, Wang J, Li Z, Qiu J, et al. Asthma does not influence the severity of COVID-19: a meta-analysis. J Asthma. (2021) 1-7. doi: 10.1080/02770903.2021.1917603

249. Huang Y, Gao L, Xie X, Tan SC. Epidemiology of dyslipidemia in Chinese adults: meta-analysis of prevalence, awareness, treatment, and control. Popul Health Metr. (2014) 12:28. doi: 10.1186/s12963-014-0028-7

250. Carroll MD, Fryar CD. Total and high-density lipoprotein cholesterol in adults: United States, 2015-2018. NCHS Data Brief, no 363. Hyattsville, MD: National Center for Health Statistics (2020). Available online at: https://www. cdc.gov/nchs/data/databriefs/db363-h.pdf

251. Tóth PP, Potter D, Ming EE. Prevalence of lipid abnormalities in the United States: the National Health and Nutrition Examination Survey 20032006. J Clin Lipidol. (2012) 6:325-30. doi: 10.1016/j.jacl.2012.05.002

252. Ludvigsson JF. Systematic review of COVID-19 in children shows milder cases and a better prognosis than adults. Acta Paediatr. (2020) 109:1088-95. doi: 10.1111/apa.15270

253. Zaigham M, Andersson O. Maternal and perinatal outcomes with COVID19: a systematic review of 108 pregnancies. Acta Obstetr Gynecol Scand. (2020) 99:823-9. doi: 10.1111/aogs.13867

Conflict of Interest: The authors declare that the research was conducted in the absence of any commercial or financial relationships that could be construed as a potential conflict of interest.

Publisher's Note: All claims expressed in this article are solely those of the authors and do not necessarily represent those of their affiliated organizations, or those of the publisher, the editors and the reviewers. Any product that may be evaluated in this article, or claim that may be made by its manufacturer, is not guaranteed or endorsed by the publisher.

Copyright (c) 2021 Geng, Yu, Bao, Feng, Yuan, Zhang, Chen, Chen, Li and Yu. This is an open-access article distributed under the terms of the Creative Commons Attribution License (CC BY). The use, distribution or reproduction in other forums is permitted, provided the original author(s) and the copyright owner(s) are credited and that the original publication in this journal is cited, in accordance with accepted academic practice. No use, distribution or reproduction is permitted which does not comply with these terms. 